\title{
Internal structures and high-velocity frictional properties of Longmenshan fault zone at Shenxigou activated during the 2008 Wenchuan earthquake
}

\author{
Yu Wang · Shengli Ma $\cdot$ Toshihiko Shimamoto $\cdot$ Lu Yao $\cdot$ Jianye Chen \\ Xiaosong Yang $\cdot$ Honglin He $\cdot$ Jiaxiang Dang $\cdot$ Linfeng Hou $\cdot$ Tetsuhiro Togo
}

Received: 9 June 2014/ Accepted: 11 August 2014/Published online: 30 September 2014

(C) The Seismological Society of China, Institute of Geophysics, China Earthquake Administration and Springer-Verlag Berlin Heidelberg 2014

\begin{abstract}
This paper reports internal structures of a wide fault zone at Shenxigou, Dujiangyan, Sichuan province, China, and high-velocity frictional properties of the fault gouge collected near the coseismic slip zone during the 2008 Wenchuan earthquake. Vertical offset and horizontal displacement at the trench site were $2.8 \mathrm{~m}$ (NW side up) and $4.8 \mathrm{~m}$ (right-lateral), respectively. The fault zone formed in Triassic sandstone, siltstone, and shale about $500 \mathrm{~m}$ away from the Yingxiu-Beichuan fault, a major fault in the Longmenshan fault system. A trench survey across the coseismic fault, and observations of outcrops and drill cores down to a depth of $57 \mathrm{~m}$ revealed that the fault zone consists of fault gouge and fault breccia of about 0.5 and $250-300 \mathrm{~m}$ in widths, respectively, and that the fault strikes $\mathrm{N} 62^{\circ} \mathrm{E}$ and dips $68^{\circ}$ to NW. Quaternary conglomerates were recovered beneath the fault in the drilling, so that the fault moved at least $55 \mathrm{~m}$ along the coseismic
\end{abstract}

Y. Wang · S. Ma $(\bowtie) \cdot$ T. Shimamoto - L. Yao - J. Chen . X. Yang $\cdot$ J. Dang $\cdot$ T. Togo

State Key Laboratory of Earthquake Dynamics, Institute of Geology, China Earthquake Administration, Beijing 100029,

China

e-mail: masl@ies.ac.cn

H. He

National Center for Active Fault Studies, Institute of Geology,

China Earthquake Administration, Beijing 100029, China

L. Hou

Earthquake Administration of Zhejiang Province,

Hangzhou 310013, Zhejiang, China

Present Address:

T. Togo

Seismotectonics Research Group, Institute of Earthquake and Volcano Geology, National Institute of Advanced Industrial Science and Technology, Tsukuba 305-8568, Japan slip zone, experiencing about 18 events of similar sizes. The fault core is composed of grayish gouge (GG) and blackish gouge (BG) with very complex slip-zone structures. BG contains low-crystalline graphite of about $30 \%$. High-velocity friction experiments were conducted at normal stresses of 0.6-2.1 MPa and slip rates of 0.1-2.1 m/ s. Both GG and BG exhibit dramatic slip weakening at constant high slip rates that can be described as an exponential decay from peak friction coefficient $\mu_{\mathrm{p}}$ to steadystate friction coefficient $\mu_{\mathrm{ss}}$ over a slip-weakening distance $D_{\mathrm{c}}$. Deformation of GG and BG is characterized by overlapped slip-zone structures and development of sharp slickenside surfaces, respectively. Comparison of our data with those reported for other outcrops indicates that the high-velocity frictional properties of the Longmenshan fault zones are quite uniform and the high-velocity weakening must have promoted dynamic rupture propagation during the Wenchuan earthquake.

Keywords Wenchuan earthquake . Longmenshan fault system · Shenxigou fault zone - Fault zone structures · High-velocity friction

\section{Introduction}

The 12 May 2008 Wenchuan $M_{\mathrm{W}} 7.9$ earthquake occurred along the Longmenshan thrust belt between Tibetan plateau and the Sichuan basin and resulted in two major surface ruptures along the Yingxiu-Beichuan fault (or Beichuan fault) of about $250 \mathrm{~km}$ in length and the Pengguan fault (or Guanxian-Anxian fault) of about $70 \mathrm{~km}$ in length (Xu et al. 2009a; Liu-Zeng et al. 2009, 2010; Lin et al. 2009; Zhang et al. 2010). Studies on the Longmenshan fault zones have been conducted on several outcrops 
to understand the nature and physical properties of fault zones that caused a large destructive earthquake (Lin et al. 2010; Togo et al. 2011a, b; Hou et al. 2012; Chen et al. 2013a, b, c; Yao et al. 2013a, b). The Chinese government launched the Wenchuan Earthquake Fault Zone Scientific Drilling (WFSD) project soon after the earthquake, and four deep holes were drilled into the fault zones with notable surface ruptures ( $\mathrm{Li}$ et al. 2013, 2014; Wang et al. 2014; Kuo et al. 2014; Si et al. 2014). In addition to those, State Key Laboratory of Earthquake Dynamics, Institute of Geology, China Earthquake Administration (IGCEA) started shallow drilling projects into Yingxiu-Beichuan fault and its subsidiary faults at Pingxi, Zhaojiagou, Xiaojiaqiao, and Shenxigou, where notable surface ruptures formed during Wenchuan earthquake (e.g., Hou et al. 2012). One of the major objectives of those studies is to describe internal structures of the Longmenshan fault zones, to determine frictional and hydraulic properties of fault core where seismic slip occurred, and eventually to understand mechanisms of the Wenchuan earthquake based on measured frictional and hydraulic properties. Many fault-zone outcrops and the drilling projects provide an excellent chance to determine lateral variation of faultzone structures and their physical properties of the Longmenshan fault zones.

The present work focuses on a large-scale fault zone in Shenxigou (Fig. 1), located at a western part of the major coseismic fault during the Wenchuan earthquake (about $12 \mathrm{~km}$ from the western end of known surface ruptures, and about $7 \mathrm{~km}$ to the southwest from the drilling sites of WFSD-1 and WFSD-2). The purpose of this work is threefold. First, we describe internal structures of a coseismic fault zone in Shenxigou during the 2008 Wenchuan earthquake and compare them to those at Bajiao Miao, Hongkou. Shenxigou is famous for a tilted country road at the edge of hanging wall of the coseismic fault with vertical displacements of 3-5 m (Liu-Zeng et al. 2010). However, there are no clear outcrops of a coseismic fault zone, and we integrate trench survey at the displaced road where an earthquake museum was constructed, a shallow drilling into the fault zone (57 $\mathrm{m}$ deep) near the trench site, and several nearby outcrops of mostly fault breccia zones. Yingxiu-Beichuan fault zone in Bajiao Miao, often described as "Hongkou outcrop", is by far the best studied outcrop in the Longmenshan fault system after the Wenchuan earthquake in describing surface ruptures of the Wenchuan earthquake (e.g., Liu-Zeng et al. 2010), faultzone outcrop studies (Togo et al. 2011a; Wang et al. 2014), and WFSD-1 and 2 (Li et al. 2013, 2014). The fault zone at Bajiao Miao is a part of Beichuan fault and is about $100 \mathrm{~m}$ wide (Li et al. 2013). However, Liu-Zeng et al. (2010, Figs. 2, 3) report very detailed maps of surface ruptures which we quoted as blue lines in Fig. 1. Surface ruptures during the Wenchuan earthquake deviate gradually from the Beichuan fault at Bajiao Miao to Shenxigou, and comparison of fault zones at both ends would be of interest in understanding the nature of fault zones at the western part of the coseismic faults. Second, we conducted textural and material analysis of the black gouge in the fault gouge close to the coseismic fault at a trench site excavated by IGCEA. Lin et al. (2010) report black gouge and complex structures in the fault gouge at the same trench site without reporting results from material analysis. The black gouge may contain carbon which has received much attention recently as a potential weakening agent of faults in addition to clay minerals (Oohashi et al. 2011, 2012, 2013).

Third, we conducted a series of high-velocity friction experiments (constant slip-rate experiments and slide-holdslide tests) and compared our results with those for several other outcrops to evaluate heterogeneity of the Longmenshan fault zones with respect to the high-velocity frictional properties. Yao et al. (2013a) compiled frictional properties of the fault zones and demonstrated that the Longmenshan fault zones are quite uniform with respect to the dramatic weakening properties at seismic slip rates, compared to the heterogeneous frictional properties at low slip rates depending on the contents of clay minerals (Zhang and He 2013). We plot our data on the diagrams of Yao et al. (2013a) to strengthen his conclusions. Heterogeneity in frictional properties can affect earthquake rupture propagation to cause populations of earthquakes (e.g., Ben-Zion 1996, 2008), but there has been no systematic work evaluating the heterogeneity for natural faults. Thus, the experiments will provide useful frictional properties in evaluating response of shallow parts of faults to the earthquake ruptures coming from depths by earthquake modeling.

\section{Shenxigou fault zone}

\subsection{Geological setting}

The Shenxigou is located at a western part of the Longmenshan Thrust Belt, developed along the boundary between Tibetan Plateau and Sichuan Basin (e.g., Burchfiel et al. 2008; Xu et al. 2009b; Zhang 2013a). Rapid uplifting of the Longmenshan mountains started at around $10 \mathrm{Ma}$ (5-12 Ma after Kirby et al. 2002; 8-11 Ma after Godard et al. 2009). The Longmenshan mountain is a reactivated Mesozoic fold and thrust belt (Chen and Wilson 1996), and the Wenchuan, Yingxiu-Beichuan, and Pengguan faults are the major active faults in the Longmenshan fault system (e.g., Densmore et al. 2007). In the study area at and near Shenxigou, Proterozoic Pengguan massif is thrust over Triassic formation across the Yingxiu-Beichuan fault 


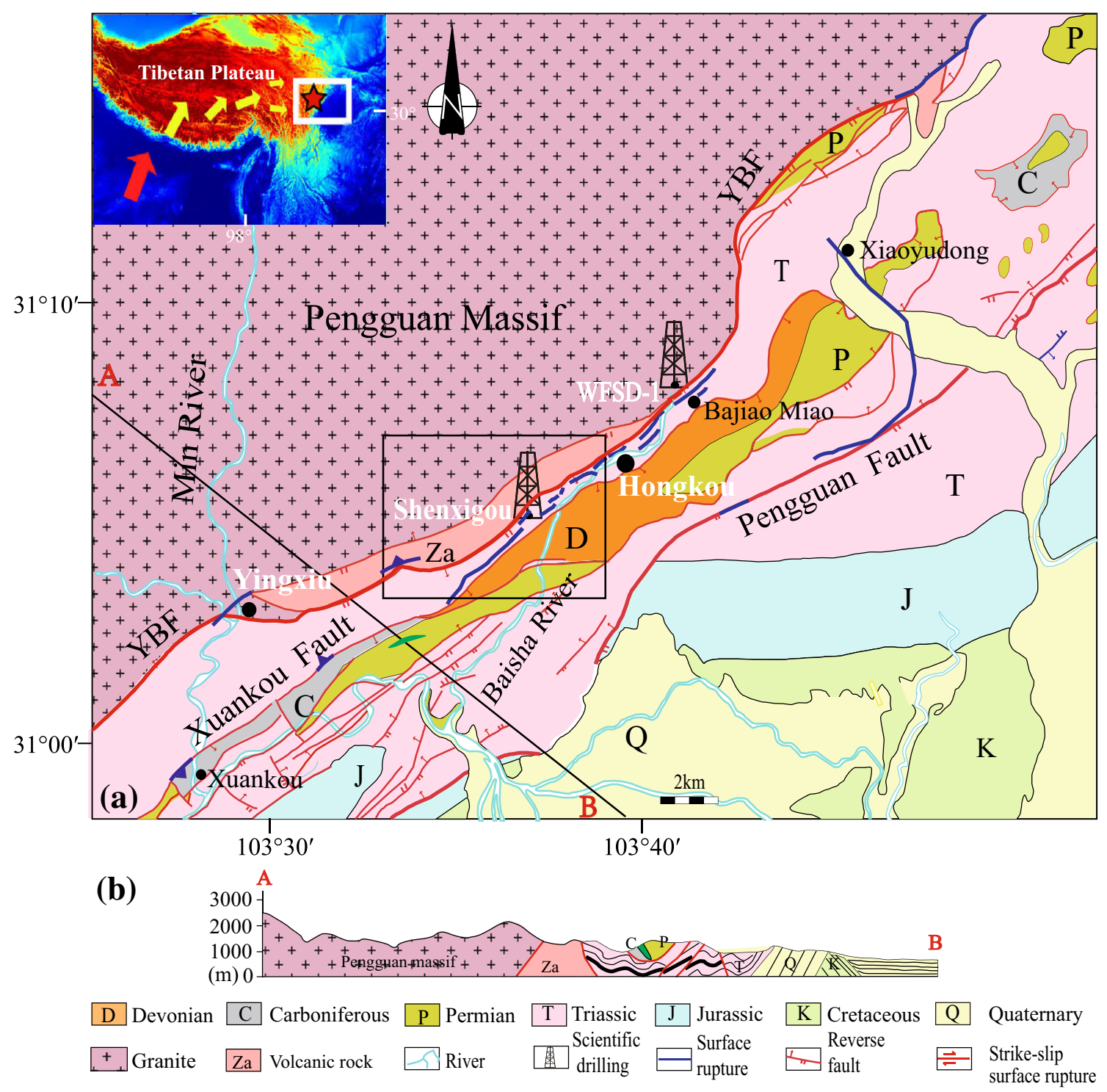

Fig. 1 a Geological map of Shenxigou and its neighboring areas in the Longmenshan mountains, Sichuan Province, China (simplified from Sichuan Bureau of Chinese Geological Survey (1976), Geological Map (1:200,000 scale) of the Guanxian area), with an inset map showing the location of the Longmenshan mountains and the Sichuan basin on a topographic map of the Tibetan plateau and north India. b A geological cross section along $\mathrm{AB}$ in (a). A thick red line marked with YBF is the Yingxiu-Beichuan fault, a major fault in the Longmenshan fault system. A single stick and double sticks on fault line indicate, respectively, the dipping direction and footwall side of a fault, from which types of faults (normal fault or reverse fault) can be distinguished. Thick blue lines are surface ruptures that formed during the 2008 Wenchuan earthquake after Liu-Zeng et al. (2010). A rectangle in (a) indicates the location of the next figure

(YBF in Fig. 1a, quoted from Sichuan Bureau of Chinese Geological Survey 1976). The fault is shown to be dipping to the southeast on a geological map (Fig. 1b). Triassic formation is thrust over Jurassic and younger formations near Baisha River across the Pengguan fault. Devonian, Carboniferous, and Permian formations are distributed in the Triassic formations as klippen structures which can be seen clearly in the two patchy distributions of the formations on top of mountains, at the northeastern corner of
Fig. 1a (marked as $\mathrm{C}$ and P). However, the distribution of the Carboniferous and Triassic formations across the Xuankou fault near the southwestern corner indicates that the boundary fault dipping at a high angle.

Shenxigou area is located at the western end of the coseismic faults during the Wenchuan earthquake (see surface rupture maps in Xu et al. 2009a; Liu-Zeng et al. 2009; Lin et al. 2009; Zhang et al. 2010). Liu-Zeng et al. (2010) report very detailed surface ruptures from Hongkou 
to Shenxigou area which we reproduced as blue lines in Fig. 1a. They report a clear surface rupture and a gentle warping, a possible surface rupture, at Yingxiu and Xuankou, respectively, and those are the western ends of confirmed surface ruptures. Surface ruptures from Shenxigou to Bajiao Miao in Hongkou are the best documented among those formed during the Wenchuan earthquake (Fig. 3 in Liu-Zeng et al. 2010). Vertical offset is 3-5 m with northwest side up in Shenxigou and Bajiao Miao, but it exhibits complex pattern locally with an opposite sense of motion (Fig. 10 of the same paper). The fault zone is documented well in Bajiao Miao where WFSD-1 and 2 holes were drilled (Togo et al. 2011a; Li et al. 2013, 2014; Wang et al. 2014). The fault zone is about $100 \mathrm{~m}$ wide, and the coseismic fault was located at the southeastern margin of the fault zone (Liu-Zeng et al. 2010; Togo et al. 2011a), but it is still part of the Yingxiu-Beichuan fault zone ( $\mathrm{Li}$ et al. 2013, 2014). However, the surface ruptures deviate from this fault and become very close to Xuankou fault near Shenxigou (follow blue lines from Bajiao Miao to Shenxigou in Fig. 1a). Surface ruptures along YingxiuBeichuan fault are not continuous at Xiaoyudong where NW-SE trending surface rupture formed connecting the surface ruptures along the Yingxiu-Beichuan and Pengguan faults. Jin et al. (2010) considered the area as a segment boundary of the Longmenshan fault system.

Figure 2a exhibits close-up of geological map of the Shenxigou area where the Pengguan massif is composed of monzogranite, plagiogranite, and volcanic rocks (rectangular portion in Fig. 1a). Distribution of the YingxiuBeichuan fault with topographic contours indicates that the fault dips to the northwest at a high angle, and we drew the fault dipping differently from that shown in Fig. 1b. Moreover, Xuankou fault is very straight in the region on the geological map, despite mountainous area with steep slopes, so we drew the fault as a steep fault in the cross section. Triassic Xujiahe group of the area consists of sandstone, siltstone, shale, and locally conglomerate, whereas Devonian formation to the southeast of the Xuankou fault consists of carbonates.

\subsection{Fault-zone structures at Shenxigou outcrops}

We now describe the structures of coseismic fault zone during the Wenchuan earthquake in Linjia mozi of the Shenxigou area (rectangular part of Fig. 2a), using the fault-rock classification of Sibson (1977). At locality 1 on a route map in Fig. 2c, He et al. (2008) reported that a country road was offset vertically by $2.8 \mathrm{~m}$ (NW side up) and was displaced right-laterally by $4.8 \mathrm{~m}$ (Fig. 3a). The displaced road is preserved in an earthquake museum now. He and his coworkers conducted a trench survey on the coseismic fault next to this displaced road, shown as "trench site" on the photograph, and we describe fault core structures at the trench in the next subsection. This area is also famous for a tilted road with a car abandoned on the road where the vertical displacement is about $5 \mathrm{~m}$ (locality 2, located at $100-200 \mathrm{~m}$ to southwest from the displaced road; He et al. 2008; Liu-Zeng et al. 2010). The coseismic fault is split into four sub-faults with vertical displacements of $1.5 \mathrm{~m}$, about $0.2 \mathrm{~m}, 1.2 \mathrm{~m}$, and about $0.2 \mathrm{~m}$ (from NW to SE sub-faults, with the NW sides up) at about $100 \mathrm{~m}$ to the northeast from the displaced road (Liu-Zeng et al. 2010, Fig. 3a in the Electronic Supplement), and their northeastern extensions were not confirmed. Those four surface ruptures are shown in blue lines in Fig. 2c, quoting the data in Fig. 3b of Liu-Zeng et al. (2010). Thus, vertical offset changes fairly rapidly along the coseismic fault.

Outcrops are limited in the area, but we confirmed several outcrops of fault breccia (localities 3-7 in Fig. 2c). There were outcrops of fault breccia on both sides of a small river, about $50 \mathrm{~m}$ to the northwest from the displaced road (locality 3), composed of broken fragment of sandstone and shale in pelitic matrix (Fig. 3c). We drilled a shallow hole between this breccia and displaced road (drilling mark in Fig. 2c). There is a house between the two coseismic faults (Fig. 3d), below which fault breccia is exposed (locally black-colored, Fig. 3e). There was a large outcrop of fault breccia of about $30 \mathrm{~m}$ in width, containing about $1 \mathrm{~m}$-wide fault gouge (locality 5, Fig. 3f). Gouge zones are rare, although we found a thin gouge in a neighboring outcrop (locality 6, Fig. 3g). There was a large outcrop of fault breccia at the foot of the mountain slope (locality 7, Fig. 3h). We recognized conglomerate at least $50 \mathrm{~m}$ thick forming waterfalls near the northwestern corner of Fig. 2c, and the fault zone is not a part of the Yingxiu-Beichuan fault. There are two outcrops of sandstone (each several meters wide) between localities 4 and 5 , but those are too small to be considered as host rocks. Thus, the fault zone is likely to be $250-300 \mathrm{~m}$ wide in the area.

\subsection{Fault-zone structures at Shenxigou trench}

A trench excavation next to the displaced road in Fig. 3a revealed fault core structures of the coseismic fault zone. Fault zone is covered by Quaternary conglomerate of 2-3 $\mathrm{m}$ in thickness, and the ground surface was flat before the Wenchuan earthquake. The fault zone has thrust over the Quaternary conglomerates along a coseismic fault dipping to $\mathrm{NW}$ by about $55^{\circ}$ on both southwest and northeast walls (Fig. 4a, c). The strike of the coseismic surface rupture is $\mathrm{N}^{\circ} 2^{\circ} \mathrm{E}$ (Fig. 3c). The fault zone on the 

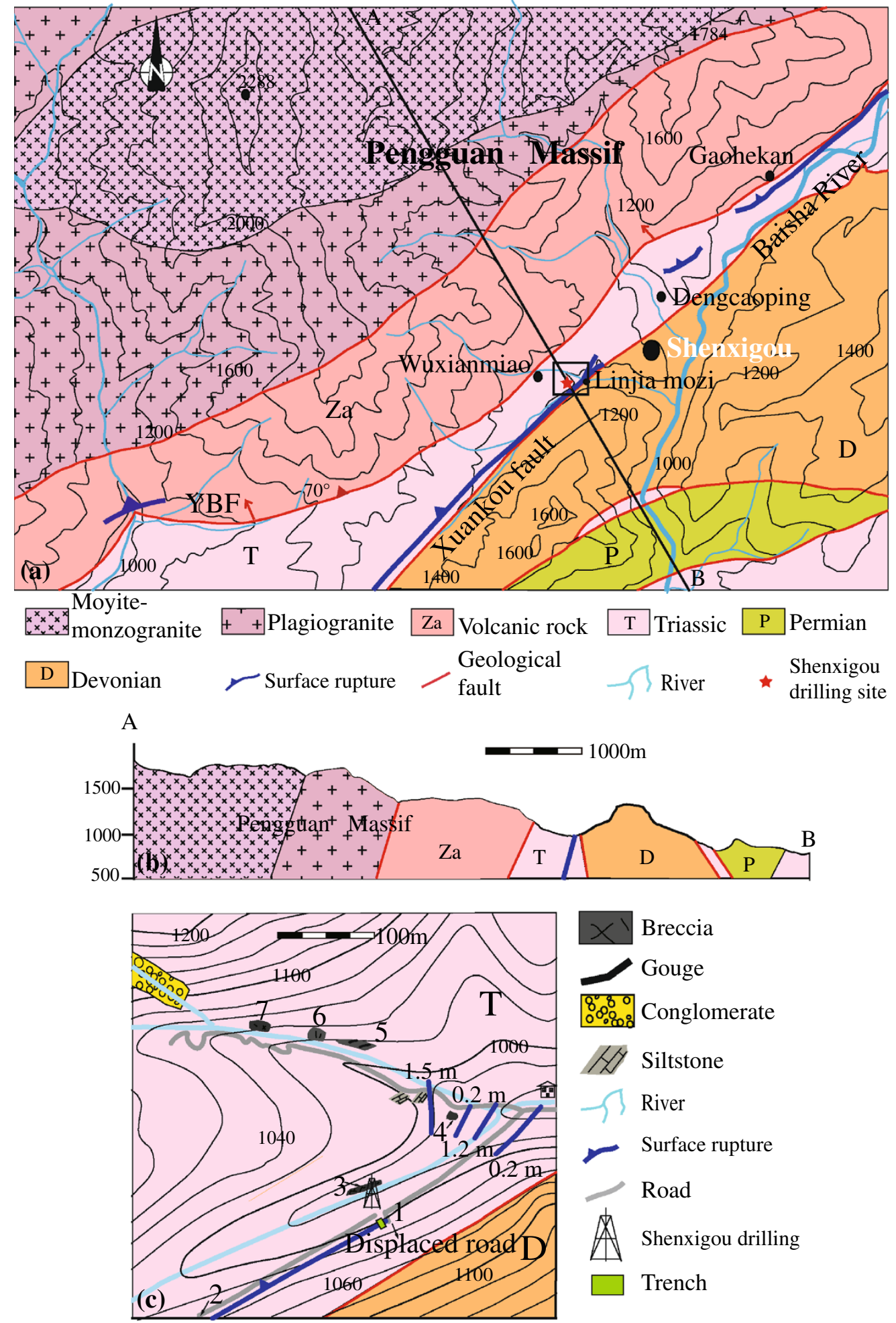

Fig. 2 a A geological map of the Shenxigou area (after Sichuan Bureau of Chinese Geological Survey 1976), b a geological cross section along $\mathrm{AB}$ in (a), and $\mathbf{c}$ a route map in Shenxigou near a coseismic fault shown in blue during the Wenchuan earthquake. Surface ruptures and displacements in (c) are after Liu-Zeng et al. (2010); the four surface ruptures and vertical displacements were taken from Electronic Supplement of the paper. We modified the cross section in (b) from the original one shown in Fig. $1 \mathrm{~b}$ for reasons explained in the text 

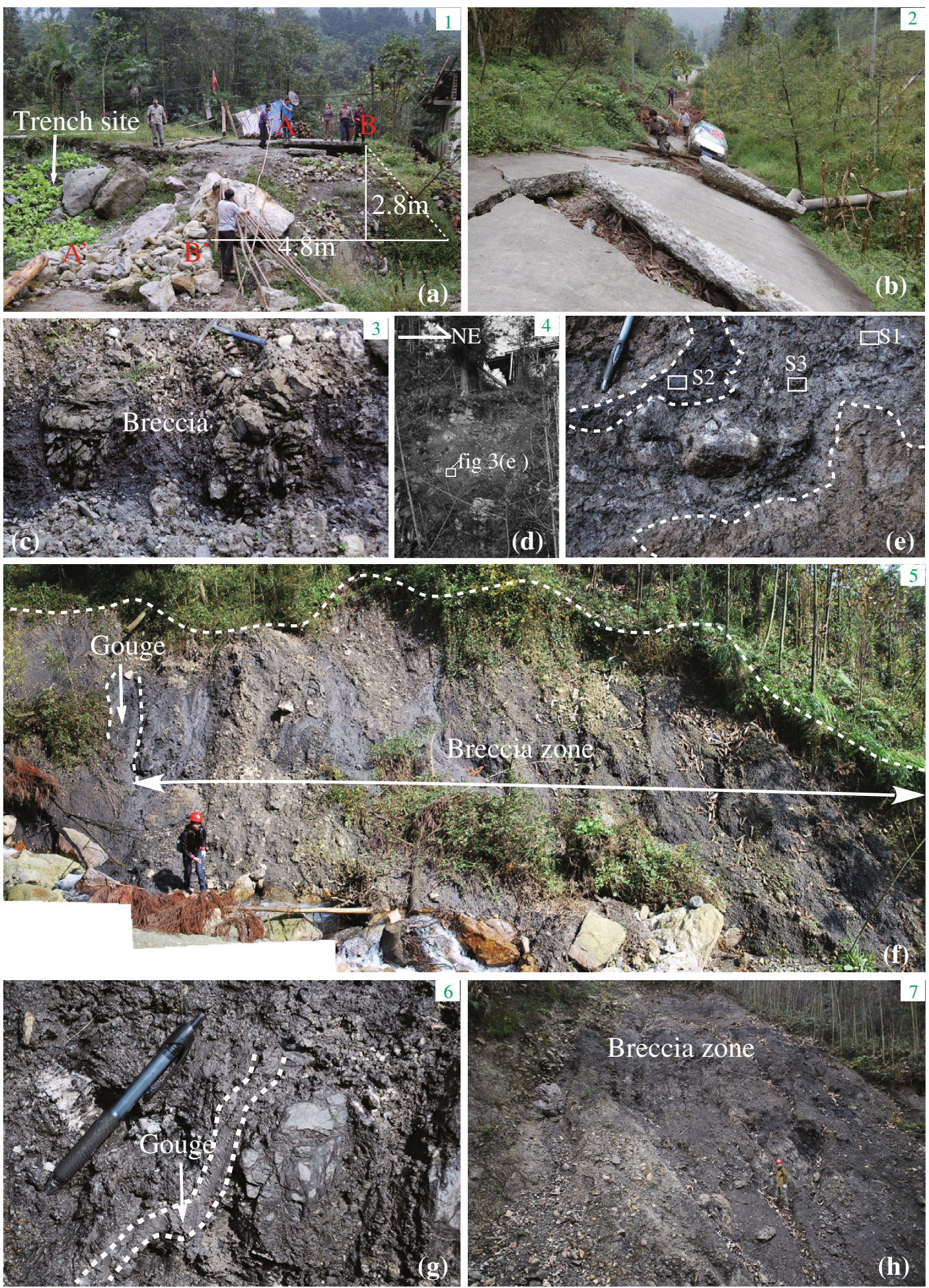

Fig. 3 a A displaced road in Shenxigou vertically and horizontally by 2.8 and $4.8 \mathrm{~m}$, respectively, during the Wenchuan earthquake (locality 1 in Fig. 2c; other localities are shown in the same figure). $A$ and $A^{\prime}$, and $B$ and $B^{\prime}$ are roughly corresponding points before the earthquake. b A tilted road along the coseismic fault (locality 2); the ground surfaces on both sides of the road were of the same level before the earthquake. Photographs showing $\mathbf{c}$ fault breccia near the drill site (locality 3), $\mathbf{d}$ an outcrop of fault breccia at locality 4, e a close up of fault breccia at the rectangular portion in (d) with locations of samples $S 1, S 2$, and $S 3$ for the X-ray diffraction (XRD) and carbon analysis in Table 1, $\mathbf{f}$ a large outcrop of fault breccia containing gouge at locality $5, \mathbf{g}$ a thin gouge in fault breccia at locality 6 , and $\mathbf{h}$ a cliff composed of fault breccia at locality 7. Numbers on the upper-right corners refer to the locality numbers in Fig. $2 \mathrm{c}$ 

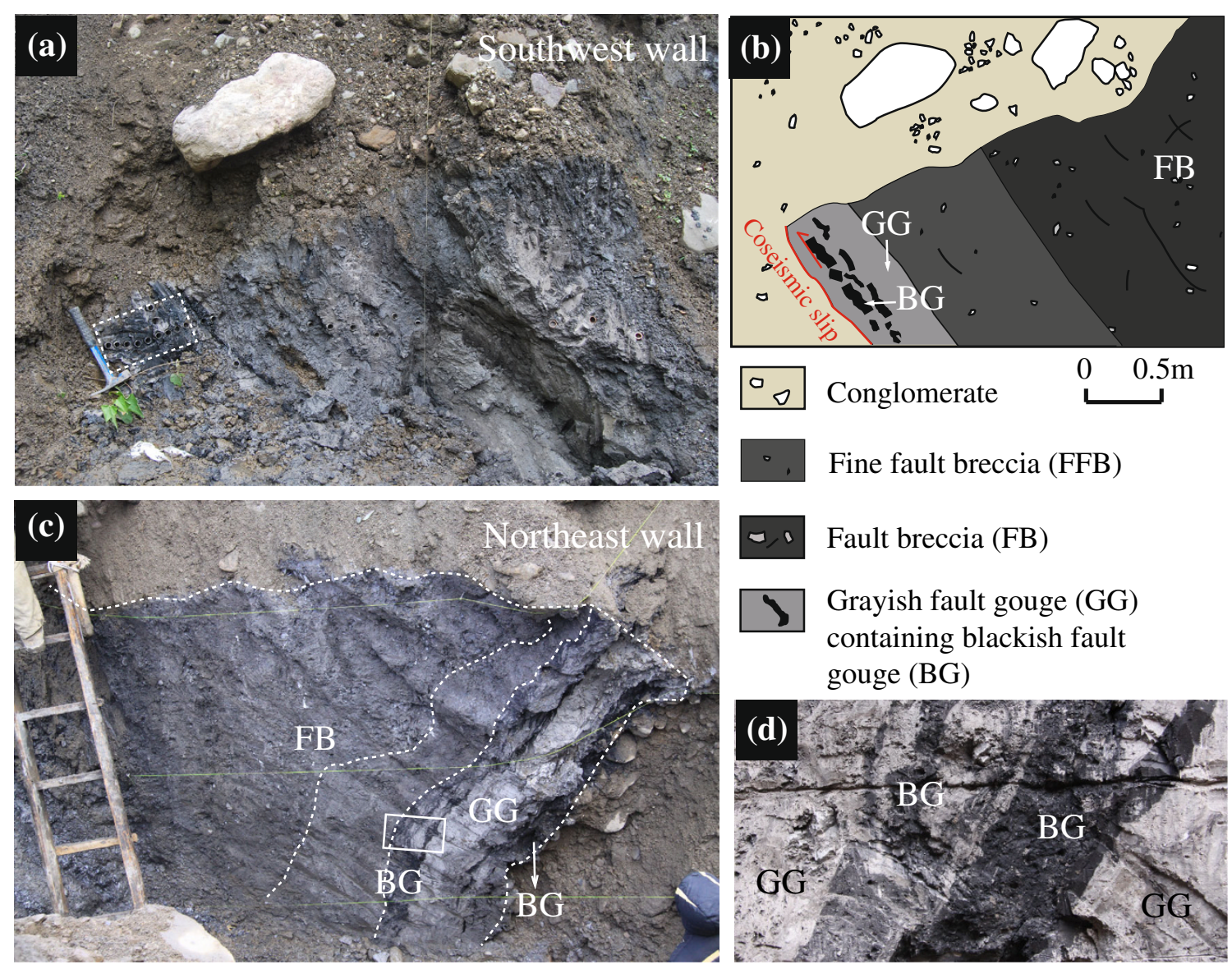

. Fine fault breccia (FFB)
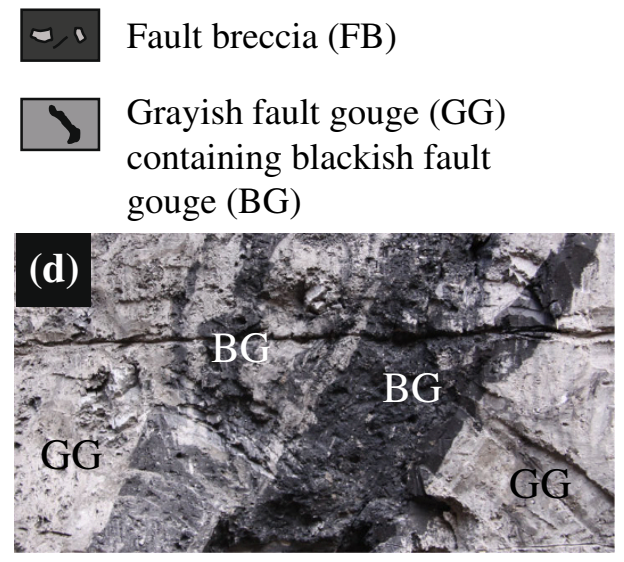

Fig. 4 a A photograph showing the southwest wall of a trench next to the displaced road (Fig. 3a), and b its sketch with fault-rock classifications. The coseismic fault during the Wenchuan earthquake is shown in red line in (b). The rectangular dashed line in (a) shows the location of a close-up photograph in Fig. 7a. c A photograph of the northeast wall of the trench, and d a close-up photograph of the rectangular portion in $(\mathbf{c})$

southwest wall (Fig. 4a, b) consists of fault gouge (about $400 \mathrm{~mm}$ wide), fine fault breccia (about $600 \mathrm{~mm}$ wide), and fault breccia (wider than $1 \mathrm{~m}$ ). The gouge is a very complex mixture of grayish gouge (GG) and blackish gouge (BG) as we show their microstructures in a later section. On the other hand, the fault zone on the northeast wall (Fig. 4c, d) is composed of fault gouge (400-700 mm wide), fine fault breccia (50-250 mm wide), and fault breccia (wider than a few meters). The gouge zone consists of GG and BG, and some BG zones occur as fracture filling.

\subsection{Shenxigou shallow drilling}

A shallow hole (57 m deep) was drilled vertically at a point $20 \mathrm{~m}$ to the northwest from the margin of the displaced road in Shenxigou (drilling marks in Figs. 1a, 2c; GPS location: $31^{\circ} 05^{\prime} 24^{\prime \prime} \mathrm{N}, 103^{\circ} 36^{\prime} 56^{\prime \prime} \mathrm{E}$ ). Drill cores of $80 \mathrm{~mm}$ in diameter were taken below about $9 \mathrm{~m}$ as shown by photographs with depths given at the top and bottom in Fig. 5. Cores of about $25 \mathrm{~m}$ in total length were recovered, but cores were not recovered at blank portions. A drilling company recorded a depth range of each cored interval down to a centimeter scale, and we put a stitched photograph of the recovered cores to the upper side of the interval in Fig. 5. Thus, the depths in the figure have uncertainty of the lengths of the missing cores. The cores consist of fault breccia and fault gouge of Triassic sandstone, siltstone and shale, intact sandstone and siltstone, and Quaternary conglomerates, as shown by different colors in Fig. 5 and by representative close-up photographs in Fig. 6a-g. Figure $6 \mathrm{~h}$ gives a cross section from the trench site, next to the displaced road, to the drill cores using the same color as in Fig. 5. Fault breccia and gouge are dark colored because they contain pelitic rocks, but we adjusted the brightness and contrast of all core photographs in Figs. 5 and 6 to exhibit fault-rock structures (clast-matrix structures in particular). Thus, the color of rocks on the 


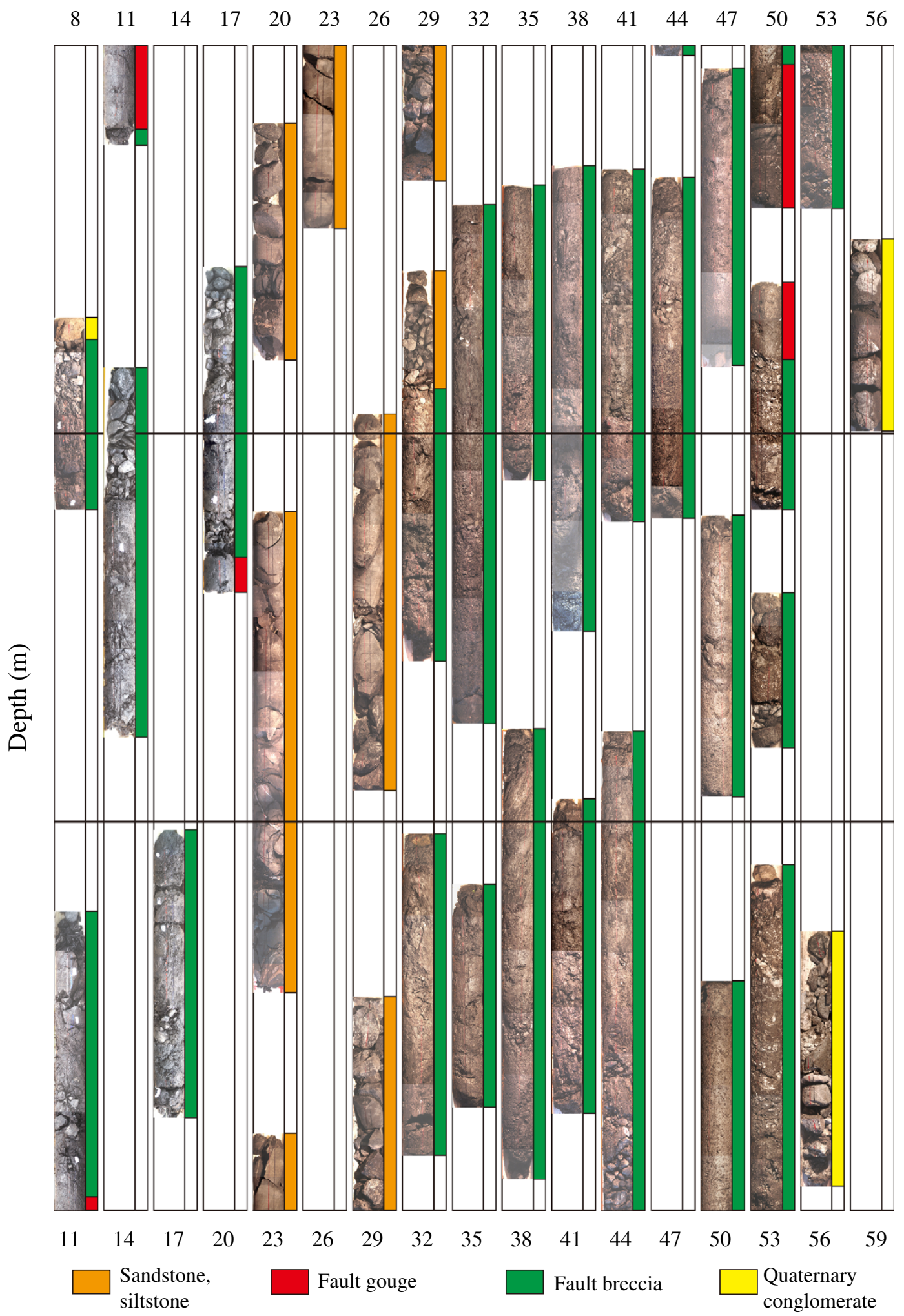

Fig. 5 Composite photographs of the shallow drill cores at Shenxigou. The drilling site was $20 \mathrm{~m}$ to the northwest from the southeastern edge of the displaced road (drilling mark in Fig. 2c). Close-up photographs of the cores were stitched to make the columns with depths in meters, given at the top and bottom. Cores were not recovered from the blank portions. Core depths are shown by putting the core photographs to the top of the depth interval of the core recovery, so that real depths of cores may be slightly lower than those shown here where some cores were not recovered 


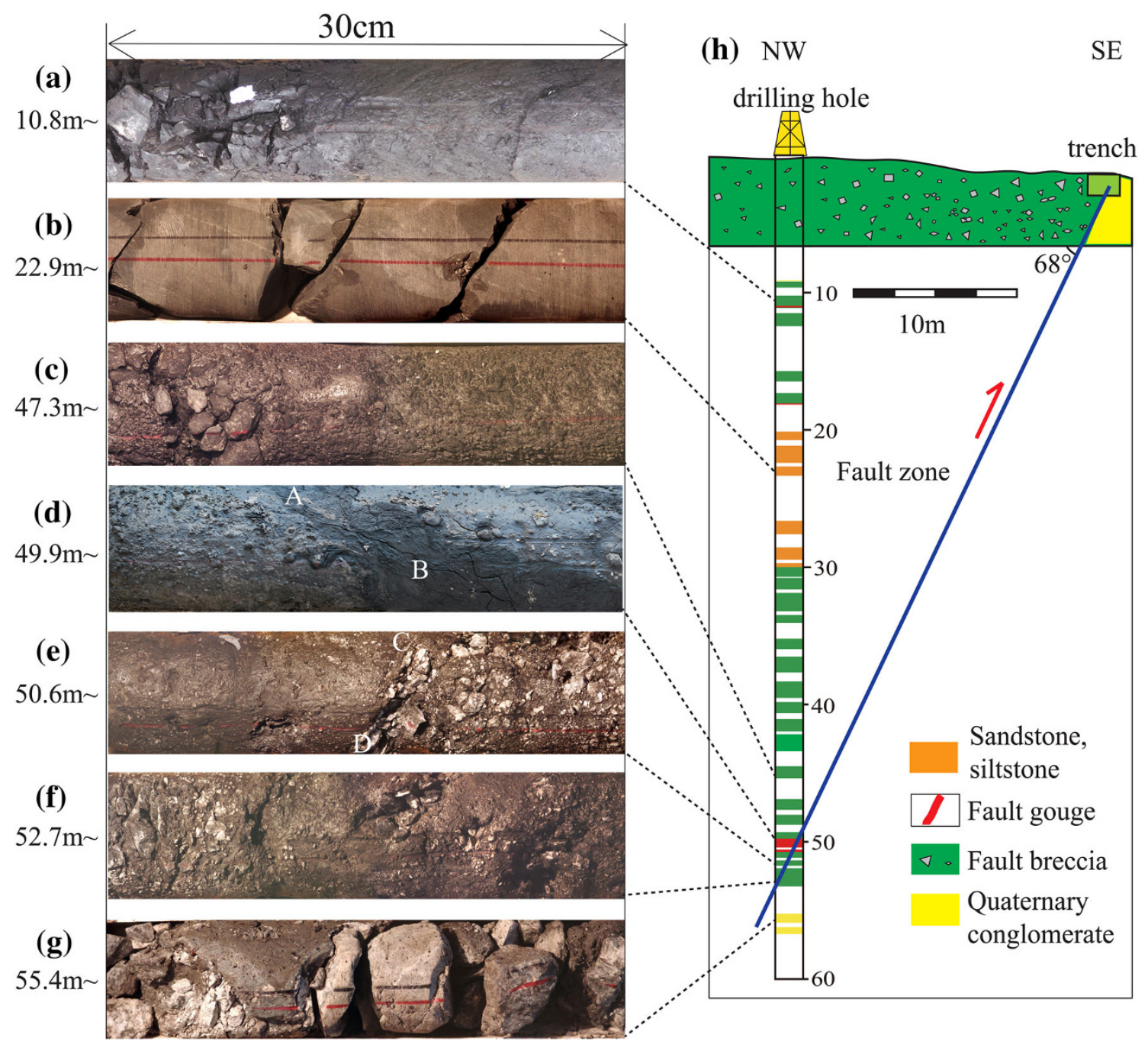

Fig. 6 a-g Close-up photographs of representative fault rocks in the shallow drill cores at Shenxigou, and $\mathbf{h}$ a schematic profile showing the distribution of fault rocks, and the relationship between the drill core and trench site. Photographs exhibit a fault breccia and fault gouge at depths of 10.8-11.1 m (their boundary at $10.96 \mathrm{~m}$ ), b a large fragment of host rock sandstone at 22.9-23.2 m, $\mathbf{c}$ fault breccia of Triassic sedimentary rocks at $44.6-44.9 \mathrm{~m}, \mathbf{d}$ the upper boundary between fault breccia and fault gouge zone near the coseismic fault at a depth of $50.05 \mathrm{~m}(\mathrm{AB}$ is the orientation of foliation in gouge, and the boundary is slightly to the left from $\mathrm{AB}$ ), e the lower boundary (CD) between the gouge zone and crushed Quaternary conglomerates at the depth of $50.81 \mathrm{~m}, \mathbf{f}$ deformed conglomerates mixed with fault gouge at 52.7-53.0 m, and $\mathbf{g}$ weakly deformed conglomerates at 55.5-55.8 $\mathrm{m}$ in depths. In this and the previous figures, brightness of the most photographs was enhanced using Photoshop software; the real color of the cores is more blackish than the color in the photographs

photographs is much lighter colored than the real color. The matrix portion of fault breccia often appears shiny because the reflected light from the fine-grained matrix is enhanced due to the change in brightness and contrast of the photographs. But its real color is black as typical of pelitic fault gouge or matrix of pelitic fault breccia.

Surface conglomerate of about $60 \mathrm{~mm}$ in thickness was recovered from a depth of $8.7 \mathrm{~m}$ (yellow stripe in Fig. 5). Cores were mostly fault breccia as shown with green color (see left half of Fig. 6a, c, to the left from AB in Fig. 6d, right half of Fig. 6e, f). Nearly, intact sandstone and siltstones were recovered for an interval of $20.2-29.8 \mathrm{~m}$ (orange color in Fig. 5, a photograph of sandstone in Fig. 6b). This is of about the same size as those of the two outcrops of sandstone between localities 4 and 5 in Fig. 2c, and is likely to be large fragments of host rocks in the fault zone. Fault gouge was recognized at three locations marked with red color in Fig. 5); i.e., at intervals of 10.97-11.22 m (250 $\mathrm{mm}$ in core interval; $60 \%$ of the core on right side of Fig. 6a), $18.31-18.40 \mathrm{~m} \mathrm{(90} \mathrm{mm),} \mathrm{and} 50.05-50.81 \mathrm{~m}$ (760 mm; right side from $A B$ in Fig. 6d, and left side from $\mathrm{CD}$ in Fig. 6e). The second gouge zone may be thicker than $90 \mathrm{~mm}$ in the core interval because cores were not recovered for an interval of $1.8 \mathrm{~m}$ immediately below the gouge 
(see the depth range in Fig. 5). Quaternary conglomerate composed of carbonate pebbles and surface soil was recovered from depths of 55.28-58.00 m (a close-up photograph in Fig. 6g). The carbonate pebbles are probably derived from the Devonian formation to the southeast of the coseismic fault (Sichuan Bureau of Chinese Geological Survey 1976), but we have not determined their ages from fossils.

Fault breccia of the conglomerate was recovered from the depths of 50.81-53.42 $\mathrm{m}$ (to the right from $\mathrm{CD}$ in Fig. 6e, f). Thus, the gouge of 50.05-50.81 $\mathrm{m}$ in depths formed at the boundary of the wide fault zone with the conglomerate. We consider CD in Fig. 6e as the material boundary between the wide fault zone with the Quaternary conglomerate because clasts below this depth are mostly broken carbonates that appear white on the photographs. The depth of this boundary fault $(50.81 \mathrm{~m})$, connected with the coseismic fault at the trench (Fig. 4), gives a dip angle of $68.5^{\circ}$ to the northwest (Fig. 6h). The boundary fault could be deeper by $0.21 \mathrm{~m}$ (or $51.02 \mathrm{~m}$ in depth) because core of this length was not recovered immediately below the core containing the boundary fault. However, a depth of $51.02 \mathrm{~m}$ gives a dip angle of $68.6^{\circ}$, almost the same as the above value. Whereas the leading edge of thrust-up fault zone at the surface is collapsed now and this makes the horizontal distance between the fault and the drill site larger by about $1 \mathrm{~m}$ (the distance becomes about $21 \mathrm{~m}$ ). Then, the dip angle of fault becomes $67.5^{\circ}$ or $67.6^{\circ}$. We therefore take $51 \mathrm{~m}$ and $68^{\circ}$ as the depth of boundary fault and the dip angle of the fault in this paper. This dip angle of fault is greater than the dip angle of gouge zone on the trench walls $\left(55^{\circ}\right)$ probably because the gouge zone is slightly bent near the surface due to the collapse of the leading edge of the thrust. Thus, the vertical displacement in the dip direction along the fault is about $55 \mathrm{~m}$, and the fault must have thrust up over the Quaternary conglomerate at least this much along this boundary fault.

The gouge at $50.05-50.81 \mathrm{~m}$ in depths is $760 \mathrm{~mm}$ long along the core (or $970 \mathrm{~mm}$ at the maximum if the interval of missing core is included). The intervals of gouge and the dipping angle of fault give the thickness of gouge zone as $284 \mathrm{~mm}$ (or $363 \mathrm{~mm}$ ). We consider about $300 \mathrm{~mm}$ as the thickness of gouge zone, and this is little thinner than the widths of gouge at the trench site $(400 \mathrm{~mm}$ on the southwest wall and $400-700 \mathrm{~mm}$ on the northeast wall in Fig. 4). The fault breccia zone of Quaternary conglomerate contains gouge from the main fault zone (Fig. 6f), indicating that tectonic erosion of the fault gouge zone took place during the thrusting over the conglomerate. Black gouge of 30-50 $\mathrm{mm}$ in width formed at the upper boundary with fault breccia, and foliation can be recognized along $A B$ in Fig. 6d. Note that clasts to the left from AB are clasts in fault breccia, whereas the clast-like fragments on the right side are fragments of rocks sticking to the surface of clayey gouge. The straight line portion of the foliation makes an angle of about $30^{\circ}$ to the core axis, and the foliation is fairly close to the orientation of the fault (the difference is about $8^{\circ}$ ). The photograph in Fig. 6d was taken under sunlight and its color is close to the real color. But the brightness and contrast of all other photographs in Figs. 5 and 6 were changed to show the fault-rock structures, as mentioned above, so that the blackish colors of cores have changed to brownish colors on the photographs.

\section{Microstructures and constituent minerals of Shenxigou fault gouge}

\subsection{Microstructures of fault gouge}

Figure 7 exhibits microstructures of fault gouge at the trench site, next to the coseismic fault during the Wenchuan earthquake (a rectangular portion in Fig. 4a). Steel pipes on a close-up photograph of the sampled portion (Fig. 7a) were used to collect sample for permeability measurements, to be reported elsewhere by a coauthor of this paper. We impregnated an about 350-mm-long sample of roughly rectangular parallelepiped shape at the red rectangle, several tens of millimeters below the piped portion. Then, nine thin sections were made nearly continuously as arranged at the bottom of Fig. 7a with the same orientations as on the outcrop; the coseismic fault during the Wenchuan earthquake is on the left end below the hammer. Dark portions and white to light-gray portions on the photographs of thin section are $B G$ and $G G$, respectively. Figure caption gives the location of microstructures using the numbers of the thin sections. Lin et al. (2010, Fig. 5) briefly report microstructures of the same gouge zones.

Figure $7 \mathrm{~b}$ shows a fragment of GG (bright portion) surrounded by BG (dark portion) in thin section 7. BG occupies the matrix portion, when the two gouge types coexist. BG fills fracture cutting through a fragment of GG (AB in Fig. 7c, thin section 8), although the fracture is not sharp and through-going near the large grain above $\mathrm{E}$ probably because the GG was not cohesive. $\mathrm{C}$ in the same photomicrograph is another GG fragment surrounded by BG along DEF. In thin section 5 in the middle part of gouge, fragments of GG are elongated and both BG and GG are foliated in the upper-right to the lower-left direction (Fig. 7d; compare the shapes of GG clasts between Fig. $7 b$ and d). In thin section 3 more closer to the coseismic fault, foliated BG and GG are folded in a complex manner. In thin section 2 fairly close to the coseismic 

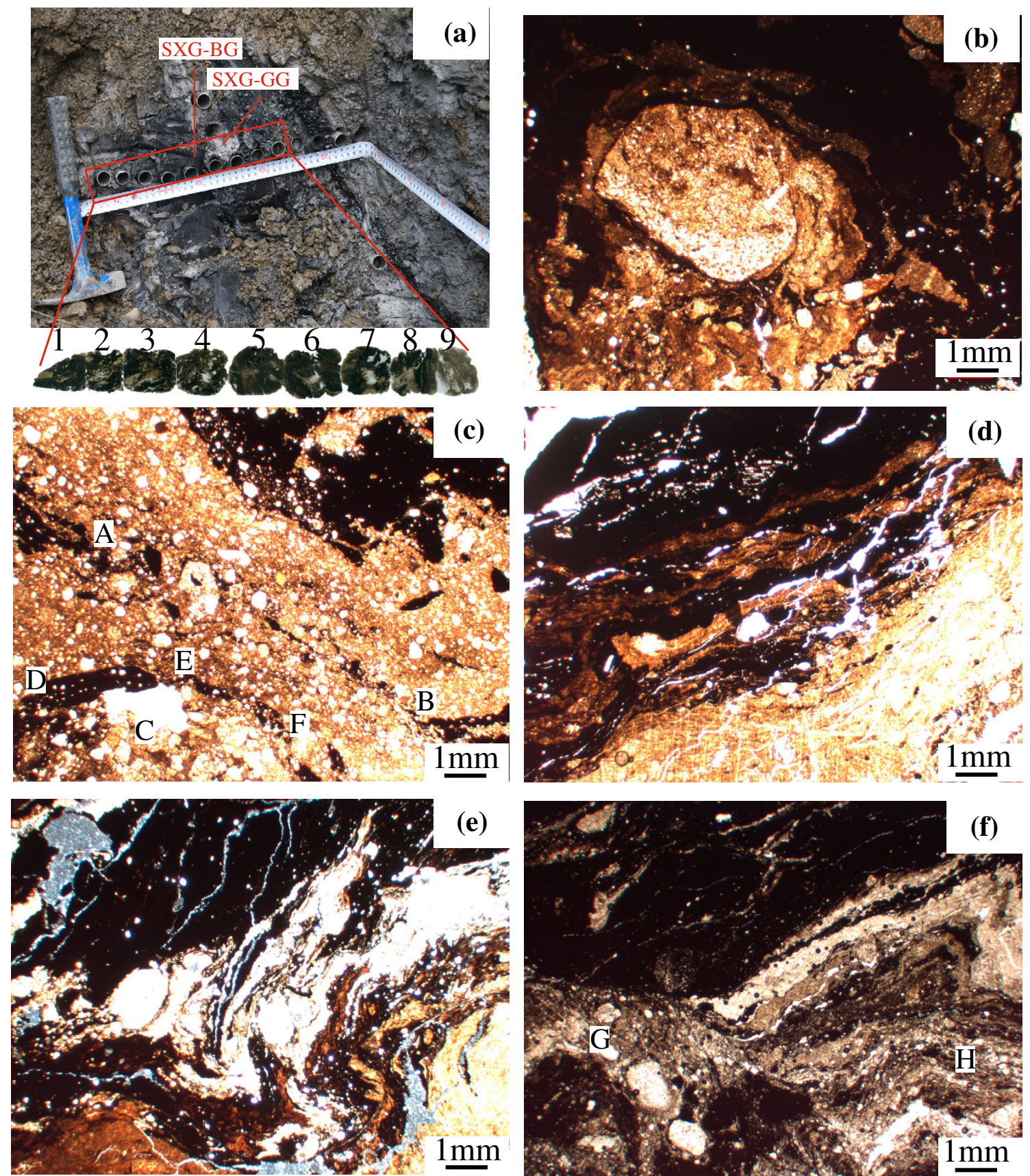

Fig. 7 Photomicrographs under plain polarized light of mixed blackish gouge (BG, dark parts) and grayish gouge (GG, bright parts), from the trench site at Shenxigou. Photograph in a exhibits sampling locations, shown by the rectangular dashed line in Fig. 4a. The coseismic fault during the Wenchuan earthquake was just below a hammer (about $330 \mathrm{~mm}$ in length). The whole sample was brought to our laboratory, samples in steel pipes were removed for other measurements, and nine large thin sections were made using samples below the pipes, from the red rectangular portion in (a), with the orientations as shown by the photographs of the numbered thin sections. Photomicrographs in (b) are from thin section 7, $\mathbf{c}$ from thin section $8, \mathbf{d}$ from thin section 5 , e from thin section 3 , and $\mathbf{f}$ from thin section 2

fault, foliated and folded BG and GG are cut by a new gouge zone in the horizontal direction (GH in Fig. 7f). Thus, the gouge close to the coseismic fault exhibits very complex over-printed deformation structures with variable orientation of foliation and fold axis.

\subsection{Results of XRD analysis}

We used samples of GG and BG collected from the gouge zone described in the previous subsection (SXG-GG and SXG-BG, respectively, in Fig. 7a) in our high-velocity 

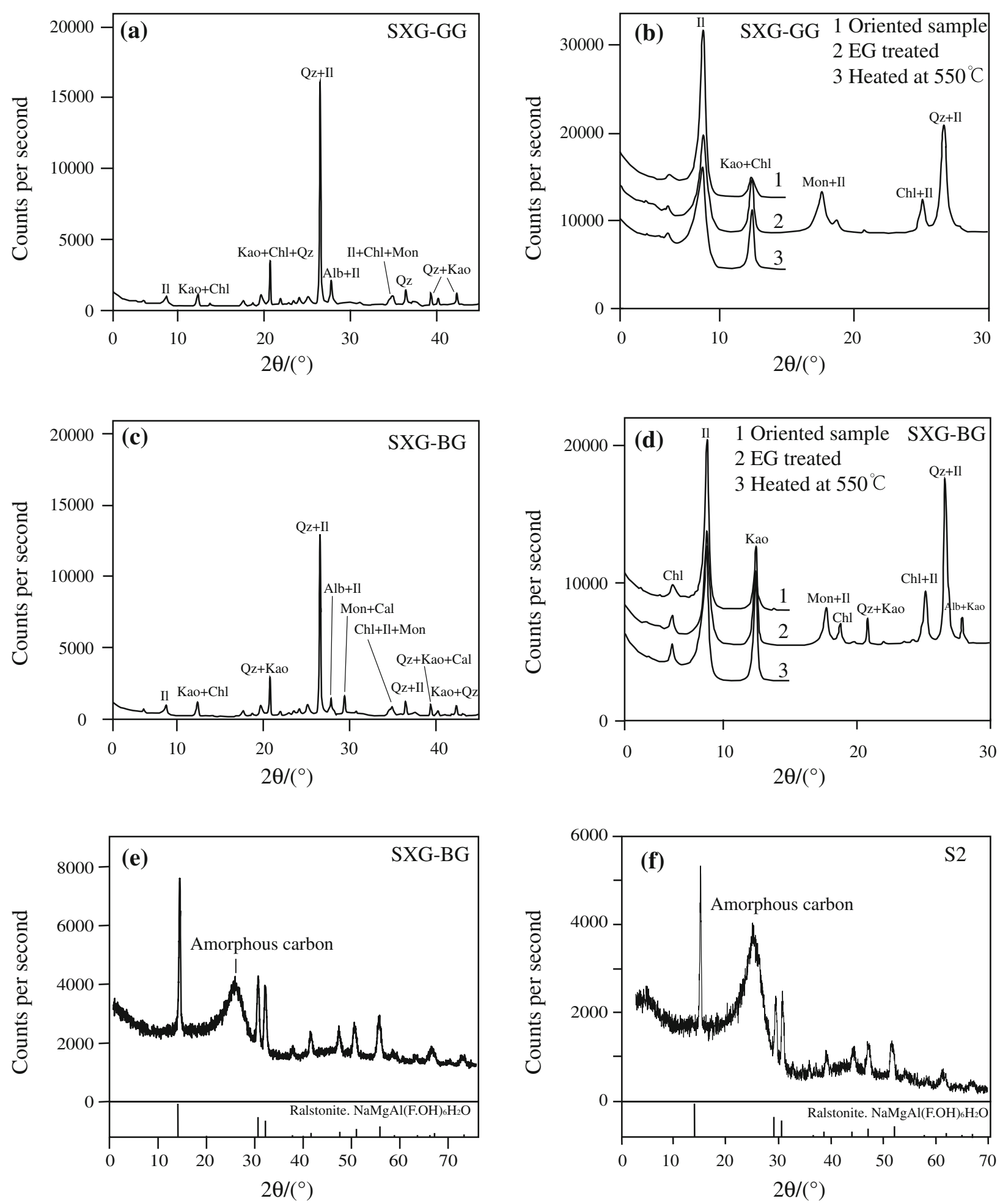

Fig. 8 X-ray diffraction (XRD) diagrams for fault gouge next to the coseismic fault; $\mathbf{a}$ and $\mathbf{b}$ for grayish gouge (SXG-GG), $\mathbf{c}$ and $\mathbf{d}$ for blackish gouge (SXG-BG), and $\mathbf{e}$ and $\mathbf{f}$ for blackish gouge (SXG-BG) and blackish fault breccia (S2), respectively, after silicates and carbonates being dissolved away. XRD diagrams in (a) and (c) are for bulk samples, whereas those in (b) and (d) are for oriented samples (1), ethylene-glycol treated samples (2) and heat-treated samples at $550{ }^{\circ} \mathrm{C}$ (3). Mineral abbreviations: $Q z$ quartz, Alb albite, Dol dolomite, $I l$ illite, $C h l$ chlorite. "Amorphous carbon" in (e) and (f) is "low-crystalline graphite" or "partially graphitized amorphous carbon". Ralstonite detected in (e) and (f) was not contained in the original sample, but it is a fluorine-containing mineral and formed during the dissolution processes of silicates with hydrofluoric acid (note good correlation of the diffraction peaks of this mineral, shown at the bottom, with diffraction peaks of our samples) 
friction experiments. A large block of sample from the central portion of the figure was brought to our laboratory, and experimental samples were collected from the interior of the block. We performed X-ray diffraction (XRD) analysis to determine mineral composition of those two types of gouge, and three samples of fault breccia at locality 4 in Fig. 2c (i.e., blackish fault breccia S1, grayish fault breccia $\mathrm{S} 2$, and fault breccia S3 intermediate between the two; see Fig. 3e for their locations). The XRD analysis was done by MicroStructure Analytical Lab, a company near Peking University in Beijing specialized for XRD analysis, using a Rigaku Rotaflex XRD instrument with JADE software. Mineral contents were determined from the intensity of the maximum peak of each mineral (or the second-strongest peak, when the maximum peak is overlapped with a peak or peaks from other minerals), using the method summarized in Moore and Reynolds (1997, chapter 9). Development of preferred orientation of platy minerals was suppressed by pushing a sample to roughened glass plate. XRD analysis on bulk samples (Fig. 8a, c) was used to determine the content of granular minerals and the total amount of clay minerals. But the types of clay minerals and their relative abundances were determined from three XRD analysis on non-treated sample, and samples with ethylene-glycol and heat treatments, using particles less than about $2 \mu \mathrm{m}$ in size, which were separated by the sedimentation method (Fig. 8b, d).

Table 1 lists mineral compositions of the five samples. Samples of GG, BG, and fault breccia contain granular minerals of $68 \%-79 \%$ (quartz, plagioclase, calcite dolomite and/or dolomite) and total amount of clay minerals of $20 \%-32 \%$ (smectite, illite-smectite mixed layer clay, illite, kaolinite and/or chlorite). All samples are rich in quartz and contain carbonates except for graying gouge (SXG-GG). Clay minerals are mostly illite-smectite mixed layer clay and illite, but chlorite of several percent is contained in BG. The analysis of mineral contents with the XRD method can have errors as much as several percent if mineral content is on the order of several tens of percent (much larger when a content is smaller), and the results in Table 1 are somewhat semi-quantitative (e.g., Moore and Reynolds 1997). Some samples contain carbonaceous materials of about $30 \%$ (next subsection), but the carbonaceous material is not included in the mineral compositions in Table 1.

\subsection{Carbon contents analysis}

Carbon in fault zones has received increasing attention recently because graphite can be a lubricating agent as effective as clay minerals at low to high slip rates (Oohashi et al. 2011, 2012, 2013). We suspected the presence of carbonaceous materials in black gouge and blackish fault breccia because of their black color and conducted carbon analysis on the five samples analyzed in the previous subsection. The carbon analysis was done at Institute of Tibetan Plateau Research, Chinese Academy of Sciences, using a TOC analyzer (Shimadzu, TOC-VCPH). Total carbon content (TC) was determined by combusting powdered samples of $100 \mathrm{mg}$ under $0.4 \mathrm{MPa}_{2}$ atmosphere at $900{ }^{\circ} \mathrm{C}$ in a combustion tube and by measuring the released $\mathrm{CO}_{2}$, whereas an inorganic carbon content (IC) was estimated by reacting a sample of the same weight with $25 \%$ phosphoric acid of $0.5 \mathrm{ml}$ in a combustion tube at $200{ }^{\circ} \mathrm{C}$ and by measuring the released $\mathrm{CO}_{2}$, following the manual of the instrument. Organic carbon content (OC) was determined by subtracting the IC content from the TC content, and it should be kept in mind that OC thus determined may contain carbon of inorganic origin.

A summary of carbon analysis in Table 1 indicates that blackish gouge (SXG-BG) and blackish fault breccia (S2) contain OC of $28.3 \%$ and $35.6 \%$ and IC of $0.5 \%$ and $0.4 \%$, respectively. Thus, their black color is probably due to the presence of carbonaceous materials. But grayish gouge (SXG-GG) and grayish fault breccia (S1) contain OC of only $0.8 \%$ and $0.7 \%$ and IC of $0 \%$ and $1.2 \%$, respectively. No

Table 1 Mineralogy and carbon contents of fault gouge from Shenxigou outcrop

\begin{tabular}{|c|c|c|c|c|c|c|c|c|c|c|c|}
\hline \multirow[t]{2}{*}{ Material } & \multicolumn{9}{|c|}{ Mineral compositions } & \multicolumn{2}{|c|}{ Carbon content } \\
\hline & Qz (\%) & $\mathrm{Pl}(\%)$ & $\mathrm{Cal}(\%)$ & Dol (\%) & Sme $(\%)$ & $\mathrm{I} / \mathrm{S}(\%)$ & Ill $(\%)$ & Kao $(\%)$ & Chl (\%) & $\begin{array}{l}\text { Organic } \\
\text { carbon }(\%)\end{array}$ & $\begin{array}{l}\text { Inorganic } \\
\text { carbon }(\%)\end{array}$ \\
\hline SXG-GG & 58 & 15 & - & - & 0.5 & 14 & 8 & 1 & 2 & 0.8 & 0.0 \\
\hline SXG-BG & 49 & 11 & 8 & - & - & 9 & 15 & 2 & 6 & 28.3 & 0.5 \\
\hline S1 & 62 & 9 & 4 & 4 & 0.8 & 2 & 11 & 2 & 4 & 0.7 & 1.2 \\
\hline $\mathrm{S} 2$ & 58 & 13 & 5 & 3 & 0.2 & 3 & 12 & 3 & 4 & 35.6 & 0.4 \\
\hline S3 & 56 & 11 & 6 & 5 & 0.5 & 2 & 14 & 1 & 5 & 16.4 & 1.0 \\
\hline
\end{tabular}

SXG-GG and SXG-BG are grayish and blackish gouge samples collected at Shexigou trench (Fig. 7a), respectively, and were used in our experiments. S1, S2, and S3 are grayish fault breccia, blackish fault breccia, and intermediate fault breccia between the two, respectively, at locality 4 in Fig. 2c (see Fig. 3e for their sampling points)

Abbreviations of minerals are $Q z$ quartz, $P l$ plagioclase, Cal calcite, Dol dolomite, Sme smectite, I/S illite-smectite mixed layer clay, Ill illite, Kao kaolinite, Chl chlorite 
IC in SXG-GG is consistent with XRD data showing no carbonates in the sample. Fault breccia sample S3 intermediate between blackish and graying fault breccias has OC and IC of $16.4 \%$ and $1.0 \%$, respectively, and its carbon contents are intermediate between those of S1 and S2.

Graphite and amorphous carbon have very different friction coefficients $\mu$ at low slip rates ( $\mu$ is about 0.1 for graphite and $0.5-0.6$ for amorphous carbon; see Oohashi et al. 2012). We thus checked if graphite is contained in the BG and blackish fault breccia or not. Graphite peaks can be missed from XRD data for the bulk samples, and we extracted carbonaceous materials in blackish gouge (SXGBG) and blackish fault breccia (S2), using the same procedures as those used in Oohashi et al. (2011). Carbonates and silicates were removed by soaking powdered samples in $17 \%$ of hydrochloric acids and in $46 \%$ of hydrofluoric acid in a draft chamber. XRD analysis of the extracted materials revealed broad peaks at $26.0^{\circ}$ and $25.2^{\circ}$ (or $d_{200}$ of 0.342 and $0.353 \mathrm{~nm}$ ) for SXG-BG and $\mathrm{S} 2$, respectively, but no (002) peak of graphite at $26.6^{\circ}$ (Fig. 8e, f; ralstonite $(\mathrm{NaMg}[\mathrm{Al}(\mathrm{F}$, $\left.\mathrm{OH})_{6}\right] \mathrm{H}_{2} \mathrm{O}$ formed during the dissolution processes of silicates with hydrofluoric acid). Both peaks of our specimens have FWHM (Full Width at Half Maximum) of $3.4^{\circ}$. Changes in crystallinity of carbon during metamorphism have been studied in very detail (e.g., Nakamura and Akai 2013; references therein). Itaya (1981) demonstrated in his studies on the Sambagawa metamorphic belt in central Shikoku, Japan, that $d_{200}$ value decreases from 0.370 to 0.375 to around 0.336 , and FWHM values drop from $8^{\circ}-11^{\circ}$ to $0.2^{\circ}-$ $0.3^{\circ}$ as the metamorphic grade increases from lower chlorite zone to biotite zone. Our specimens correspond to pumpellyite-free upper chlorite zone, close to garnet zone (Itaya 1981, Fig. 6). Nakamura and Akai (2013) showed through XRD, Raman spectroscopy, and high-resolution TEM studies on thermal metamorphic rocks that the graphitization did not proceed uniformly (their TEM photomicrographs revealed local formation of graphite in amorphous carbon clearly). Our carbon analysis is preliminary, but the results in Fig. 8e and $\mathrm{f}$ in view of previous studies indicate that carbon in Shenxigou is low-crystalline graphite or partially graphitized amorphous carbon. BG near the coseismic fault during the Wenchuan earthquake and blackish fault breccia in the interior of fault zone are quite similar in the carbon contents and in the type of constituent minerals.

\section{High-velocity friction experiments on Shenxigou fault gouge}

\subsection{Experimental procedures and conditions}

We report here 23 friction experiments at constant slip rates $v$ of $0.1-2.1 \mathrm{~m} / \mathrm{s}$ and normal stresses $\sigma_{\mathrm{n}}$ of
0.6-2.1 MPa under room humidity conditions on grayish fault gouge (GG) and blackish fault gouge (BG), collected at locations SXG-GG and SXG-BG in Fig. 7a (Table 2 for a summary of experiments). Slightly less deformed samples from the middle to inner part of the gouge zone at the trench site, close to the coseismic fault, were used to explore the frictional properties of more deformed gouge very close to the coseismic fault (see Fig. 7b, c for their deformation structures). We also conducted 10 slide-holdslide (SHS) tests on GG and BG at $v=2.1 \mathrm{~m} / \mathrm{s}$ and $\sigma_{\mathrm{n}}=1 \mathrm{MPa}$ with hold time $t_{\mathrm{h}}$ ranging from 0.3 to $14,400 \mathrm{~s}$, to determine how rapidly the frictional strength is recovered following a seismic fault motion (a summary in Table 3). All experiments were conducted using a rotaryshear low to high-velocity frictional testing apparatus at the State Key Laboratory of Earthquake Dynamics, Institute of Geology, China Earthquake Administration (see Hou et al. (2012) and Yao et al. (2013a) for details of the apparatus). We followed experimental procedures of Yao et al. (2013a, b) for both types of tests. Briefly, the apparatus is capable of producing slip rates of $60 \mathrm{~mm} / \mathrm{a}$ to $2.1 \mathrm{~m} / \mathrm{s}$ on a pair of cylindrical specimens of $40 \mathrm{~mm}$ in diameter, by changing the speed of a $22 \mathrm{~kW}$ servo-motor and using three gear-belt assemblies. The motor speed was controlled by imposing a voltage output in the controller and it took about $0.2 \mathrm{~s}$ to increase a rate of revolution from zero to the maximum speed of $1,500 \mathrm{rpm}$ and took about the same time to decrease the rate back to zero. We used equivalent slip rate (Shimamoto and Tsutsumi 1994; Hirose and Shimamoto 2005) to describe slip rate or velocity.

Gouge samples were dried in an oven for about $24 \mathrm{~h}$ at $60{ }^{\circ} \mathrm{C}$ and were gently disaggregated to make gouge powder. Gouge particles $<150 \mu \mathrm{m}$ were selected for experiments using a 100-mesh sieve to avoid having too large particles in thin gouge layer. Gouge powder was kept in the air with room humidity before experiments. We used $2.5 \mathrm{~g}$ gouge powder to make a gouge layer of about $1.2 \mathrm{~mm}$ in thickness between a pair of solid cylinders of Shangxi dolerite, composed of plagioclase, hornblende, and clinopyroxene, and small amounts of quartz and biotite. Specimens of 39.97-39.99 $\mathrm{mm}$ in an outer diameter were prepared with a cylindrical grinder with a diamond wheel, and their sliding surfaces were roughened by grinding with 100-carborundum powder. We used a Teflon sleeve with an inner diameter made smaller than the diameter of the dolerite specimen by about $150 \mu \mathrm{m}$ to impose external pressure to contain the gouge. Measured torque was corrected for the friction between the Teflon sleeve and moving specimen to determine the shear stress on the gouge using an intercept method (see Appendix of Sawai et al. (2012) for details of the correction). Correction of Teflon friction during SHS tests is more complex, and we followed the procedures described in Yao et al. (2013b, 
Table 2 A summary of experimental conditions and slip-weakening parameters on grayish gouge (GG) and blackish gouge (BG) from the fault core of Shenxigou trench

\begin{tabular}{|c|c|c|c|c|c|c|c|}
\hline Run No. & Gouge type & $\sigma_{\mathrm{n}}(\mathrm{MPa})$ & $v(\mathrm{~m} / \mathrm{s})$ & $\mu_{\mathrm{p}}$ & $\mu_{\mathrm{ss}}$ & $D_{\mathrm{c}}(\mathrm{m})$ & Gouge leakage (\%) \\
\hline LHV291 & GG & 1.0 & 2.10 & 0.60 & 0.10 & 4.90 & Almost no leak \\
\hline HLV466 & GG & 1.0 & 1.40 & 0.53 & 0.16 & 5.18 & Almost no leak \\
\hline LHV293 & GG & 1.0 & 0.80 & 0.39 & 0.21 & 2.58 & $20 \%$ \\
\hline LHV465 & GG & 1.0 & 0.8 & 0.49 & 0.19 & 7.16 & Almost no leak \\
\hline LHV294 & GG & 1.0 & 0.50 & - & - & - & $30 \%$ \\
\hline LHV295 & GG & 1.0 & 0.30 & - & - & - & $50 \%$ \\
\hline LHV296 & GG & 1.0 & 0.10 & - & - & - & $70 \%$ \\
\hline LHV299 & GG & 1.40 & 1.40 & 0.57 & 0.12 & 4.41 & Almost no leak \\
\hline LHV300 & GG & 0.60 & 1.40 & 0.44 & 0.13 & 5.33 & Almost no leak \\
\hline LHV301 & GG & 2.10 & 1.40 & 0.48 & 0.14 & 3.16 & Almost no leak \\
\hline LHV302 & GG & 0.80 & 1.40 & 0.46 & 0.14 & 5.91 & Almost no leak \\
\hline LHV488 & GG & 1.80 & 1.40 & 0.50 & 0.13 & 2.92 & Almost no leak \\
\hline LHV491 & BG & 1.00 & 2.10 & 0.46 & 0.06 & 9.81 & Almost no leak \\
\hline LHV492 & BG & 1.00 & 1.40 & 0.48 & 0.11 & 7.81 & Almost no leak \\
\hline LHV497 & BG & 2.10 & 1.40 & 0.49 & 0.12 & 3.71 & Almost no leak \\
\hline LHV498 & BG & 1.80 & 1.40 & 0.51 & 0.09 & 7.53 & Almost no leak \\
\hline LHV499 & BG & 1.40 & 1.40 & 0.54 & 0.14 & 7.16 & Almost no leak \\
\hline LHV500 & BG & 0.80 & 1.40 & 0.52 & 0.13 & 17.93 & Almost no leak \\
\hline LHV501 & BG & 0.60 & 1.40 & 0.47 & 0.14 & 22.32 & Almost no leak \\
\hline LHV502 & BG & 1.00 & 0.80 & 0.56 & 0.22 & 16.89 & Almost no leak \\
\hline LHV503 & BG & 1.00 & 0.50 & - & - & - & Almost no leak \\
\hline LHV504 & BG & 1.00 & 0.30 & - & - & - & $60 \%$ \\
\hline LHV506 & BG & 1.00 & 0.10 & - & - & - & $70 \%$ \\
\hline
\end{tabular}

The amount of gouge leakage (percentile fraction of lost gouge) was estimated roughly from the axial displacement record during experiments Symbols listed in the table are $\sigma_{\mathrm{n}}$ normal stress, $v$ slip rate, $\mu_{\mathrm{p}}$ peak friction coefficient, $\mu_{\mathrm{ss}}$ steady-state friction coefficient, $D_{\mathrm{c}}$ slip-weakening distance

Appendix A). Gouge leakage was estimated roughly in the axial displacement records during the experiments and is given in Tables 2 and 3. The gouge loss was not serious at seismic slip rates of $1.0-2.1 \mathrm{~m} / \mathrm{s}$, although some gouge was lost during tests at subseismic slip rates, notably at $0.1-0.5 \mathrm{~m} / \mathrm{s}$. However, the gouge leakage was serious at slow slip rates of $0.4-14 \mathrm{~mm} / \mathrm{s}$ particularly for GG and we do not report our preliminary results here at those slip rates.

We recorded torque (shear stress), axial force (normal stress), axial displacement (change in specimen length), and encoder and potentiometer outputs (slip rate and fault displacement) in Kyowa Universal Recorder EDX-100A with $1 \mathrm{kHz}$ sampling frequency. In rotary-shear friction experiments, measured torque fluctuates at each revolution of the specimen due to imperfect alignment of the specimens and Teflon sleeve. We removed the fluctuation following the smoothing procedures used in Yao et al. (2013a, Fig. 7a), by taking a moving average for the number of data $N$ corresponding to one revolution of a specimen. For instance, the number of data per revolution is 40 if motor speed is $1,500 \mathrm{rpm}$ ( $25 \mathrm{rps}$, equivalent slip rate of $2.1 \mathrm{~m} / \mathrm{s}$ ), we took moving average of 40 data for all data after the first revolution. This effectively smoothed out the fluctuation as demonstrated in Fig. 7a in Yao et al. (2013a). Only smoothed data are shown in our paper, but the original and smoothed curves are quite similar to those shown in their paper.

\subsection{Experimental results at constant slip rates}

We conducted two series of experiments on GG and BG under the same conditions (Table 2; Fig. 9). Figure 9a and b exhibits photographs of GG (LHV465) and BG (LHV501) deformed at normal stresses $\sigma_{\mathrm{n}}=1.0$ and $0.6 \mathrm{MPa}$ and at slip rates $v=0.8$ and $1.4 \mathrm{~m} / \mathrm{s}$, respectively. The upper specimens of the rotary side (specimen on the right sides) were removed carefully not to disturb the gouge which can be seen within the Teflon sleeve. Very shiny slickenside surfaces with circular striations formed in BG (Fig. 9b), but not in GG (Fig. 9a). Their microstructures will be described later. The first series of tests were performed at $v=1.4 \mathrm{~m} / \mathrm{s}$ and at $\sigma_{\mathrm{n}}$ ranging from 0.6 to 
Table 3 Slip-weakening parameters for the grayish gouge (GG) and blackish gouge (BG) during the first slide and during the second slide after the specimen was held under the same normal stress for a hold time $t_{\mathrm{h}}$

\begin{tabular}{|c|c|c|c|c|c|c|c|c|c|c|c|}
\hline \multirow[t]{2}{*}{ Run No. } & \multirow[t]{2}{*}{ Gouge type } & \multicolumn{4}{|c|}{ First slide } & \multirow[t]{2}{*}{ Hold time $t_{\mathrm{h}}(\mathrm{s})$} & \multicolumn{4}{|c|}{ Second slide } & \multirow[t]{2}{*}{$\Delta \mu$} \\
\hline & & $\mu_{\mathrm{p}}$ & $\mu_{\mathrm{ss}}$ & $D_{\mathrm{c}}(\mathrm{m})$ & Gouge leakage (\%) & & $\mu_{\mathrm{p}}$ & $\mu_{\mathrm{ss}}$ & $D_{\mathrm{c}}(\mathrm{m})$ & Gouge leakage (\%) & \\
\hline LHV474 & GG & 0.41 & 0.09 & 4.8 & Almost no leak & 3,600 & 0.72 & 0.17 & 8.36 & Almost no leak & 0.63 \\
\hline LHV475 & GG & 0.41 & 0.08 & 4.96 & Almost no leak & 7,200 & 0.64 & 0.19 & 8.19 & Almost no leak & 0.56 \\
\hline LHV476 & GG & 0.39 & 0.11 & 3.81 & Almost no leak & 14,400 & 0.55 & 0.19 & 3.74 & Almost no leak & 0.44 \\
\hline LHV485 & GG & 0.40 & 0.13 & 3.94 & Almost no leak & 0.3 & 0.27 & 0.15 & 0.21 & Almost no leak & 0.14 \\
\hline LHV515 & GG & 0.43 & 0.13 & 3.09 & Almost no leak & 300 & 0.57 & 0.22 & 3.42 & Almost no leak & 0.44 \\
\hline LHV507 & BG & 0.55 & 0.02 & 16.04 & Almost no leak & 0.3 & 0.17 & - & - & $10 \%$ & 0.15 \\
\hline LHV508 & BG & 0.52 & 0.12 & 10.50 & Almost no leak & 300 & 0.52 & 0.19 & 1.50 & Almost no leak & 0.40 \\
\hline LHV511 & BG & 0.53 & 0.10 & 10.82 & Almost no leak & 14,400 & 0.51 & 0.12 & 9.57 & Almost no leak & 0.41 \\
\hline LHV514 & BG & 0.54 & 0.13 & 8.75 & Almost no leak & 3,600 & 0.50 & - & - & Almost no leak & 0.37 \\
\hline LHV518 & BG & 0.52 & 0.14 & 9.93 & Almost no leak & 7,200 & 0.51 & - & - & Almost no leak & 0.37 \\
\hline
\end{tabular}

The first and second tests were all conducted at a normal stress of $1 \mathrm{MPa}$ and a slip rate of $2.1 \mathrm{~m} / \mathrm{s} . \sigma_{\mathrm{n}}, v, \mu_{\mathrm{p}}, \mu_{\mathrm{ss}}, D_{\mathrm{c}}$, and $t_{\mathrm{h}}$ are normal stress, slip rate, peak friction coefficient, steady-state friction coefficient, slip-weakening distance, and hold time, respectively. $\Delta \mu=\left(\mu_{\mathrm{p}, 2 \mathrm{nd}}-\mu_{\mathrm{ss}, 1 \mathrm{st}}\right)$ denotes the change in the friction coefficient from the steady-state value $\mu_{\mathrm{ss}, 1 \mathrm{st}}$ during the first slide to the peak value $\mu_{\mathrm{p}, 2 \text { nd }}$ during the second slide

2.1 $\mathrm{MPa}$, to study the effect of normal stress on friction (Fig. 9c, d). The second series of tests were done at $\sigma_{\mathrm{n}}=1 \mathrm{MPa}$ and by varying $v$ from 0.1 to $2.1 \mathrm{~m} / \mathrm{s}$, to see the effect of slip rate on friction (Fig. 9e, f).

Both GG and BG mostly exhibit nearly exponential slip weakening from the peak friction coefficient $\mu_{\mathrm{p}}$ to the steady-state friction coefficient $\mu_{\mathrm{ss}}$ over a slip-weakening distance $D_{\mathrm{c}}$, as expressed by

$\mu(d)=\mu_{\mathrm{ss}}+\left(\mu_{\mathrm{p}}-\mu_{\mathrm{ss}}\right) \exp \left(\ln (0.05) d / D_{\mathrm{c}}\right)$,

where $\mu$ is the friction coefficient and $d$ is displacement after the peak friction (Mizoguchi et al. 2007). $D_{\mathrm{c}}$ is defined as the displacement at which friction reduces from the peak friction coefficient by $95 \%$ of $\left(\mu_{\mathrm{p}}-\mu_{\mathrm{ss}}\right)$. Equation (1) at $d=D_{\mathrm{c}}$ gives $\left[\mu\left(D_{\mathrm{c}}\right)-\mu_{\mathrm{ss}}\right]=0.95\left(\mu_{\mathrm{p}}-\mu_{\mathrm{ss}}\right)$, confirming the definition of $D_{\mathrm{c}}$. In determining slip-weakening parameters, we first took $\mu_{\mathrm{p}}$ at the maximum friction coefficient in an experimental result and determined $\mu_{\mathrm{ss}}$ and $D_{\mathrm{c}}$ with the least-squares fitting using the Origin software. Figure 10 gives representative examples of reasonably good fitting (shown in pink curves; the correlation coefficient $R>0.9$ ) and poor fitting (shown in blue curves; $R<0.9$ ) for $\mathrm{GG}$ and $\mathrm{BG}$. Irregular behaviors with poor fitting could be due to the loss of gouge or distortion of Teflon sleeve. Gouge leaked in LHV293 which is used as an example of poor fitting in Fig. 10a. Gouge also leaked in LHV294 with a strange behavior (light-blue curve in Fig. 9e). Thus, we do not report slip-weakening parameters for six runs with gouge leakage in this paper (Table 2). However, Yao et al. (2013a) recognized that a very complex frictional behavior was associated with very complex deformation textures in gouge zone caused by shifting of slip zones (work on Pingxi gouge from the Longmenshan fault system). Therefore, the complex behaviors are not entirely caused by experimental procedures and we report all data unless we lost all gouge in experiments. The erratic behaviors are more notable for BG than for GG (cf. Fig. 9c, d). BG exhibits abrupt drop in friction followed by a recovery of friction (repeated once or twice), and then the final weakening (e.g., LHV501 in Fig. 9d). Such behaviors are somewhat similar to those of black gouge from the Pingxi outcrop of the Longmenshan fault system (Yao et al. 2013a, Fig. 9).

Shear stresses at the peak and steady-state friction were determined from $\mu_{\mathrm{p}}$ and $\mu_{\mathrm{ss}}$ and are plotted against the normal stress for GG and BG in Fig. 9g and h, respectively. In all cases, shear stress is proportional to the normal stress, and the intercepts for the peak and steady-state friction for GG are $0.25 \pm 0.07$ and $0.07 \pm 0.02$ and those for BG are $0.11 \pm 0.03$ and $0.05 \pm 0.03$, respectively. We interpret that the deviation from the friction law is due to the Teflon friction and used those intercept values for correcting the Teflon friction (the intercept values are on the same ranges as those of other workers; see Sawai et al. 2012, Table A1). After the correction, the shear versus normal stress relationships go through the origin with the peak and steadystate friction coefficients of $0.50 \pm 0.05$ and $0.14 \pm 0.01$ for GG, and $0.50 \pm 0.02$ and $0.12 \pm 0.02$ for $\mathrm{BG}$, respectively (Fig. 9g, h).

GG exhibits marked slip weakening at slip rates $v$ of 0.8 , 1.4 , and $2.1 \mathrm{~m} / \mathrm{s}$ (Fig. 9e; Table 2 for a summary of slipweakening parameters), in a similar manner as observed at $v=1.4 \mathrm{~m} / \mathrm{s}$ in Figs. 9c. Whereas the behaviors are more complex at subseismic slip rates of $0.1-0.5 \mathrm{~m} / \mathrm{s}$; this is a 
(a)

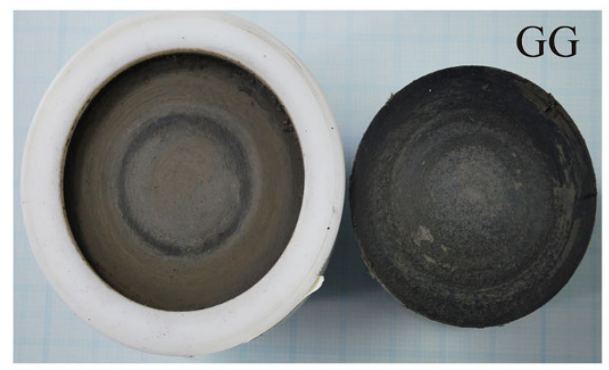

(c)

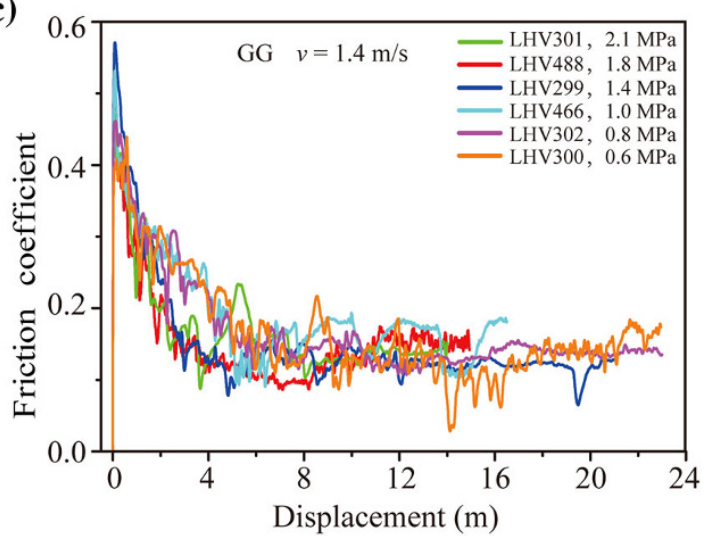

(e)
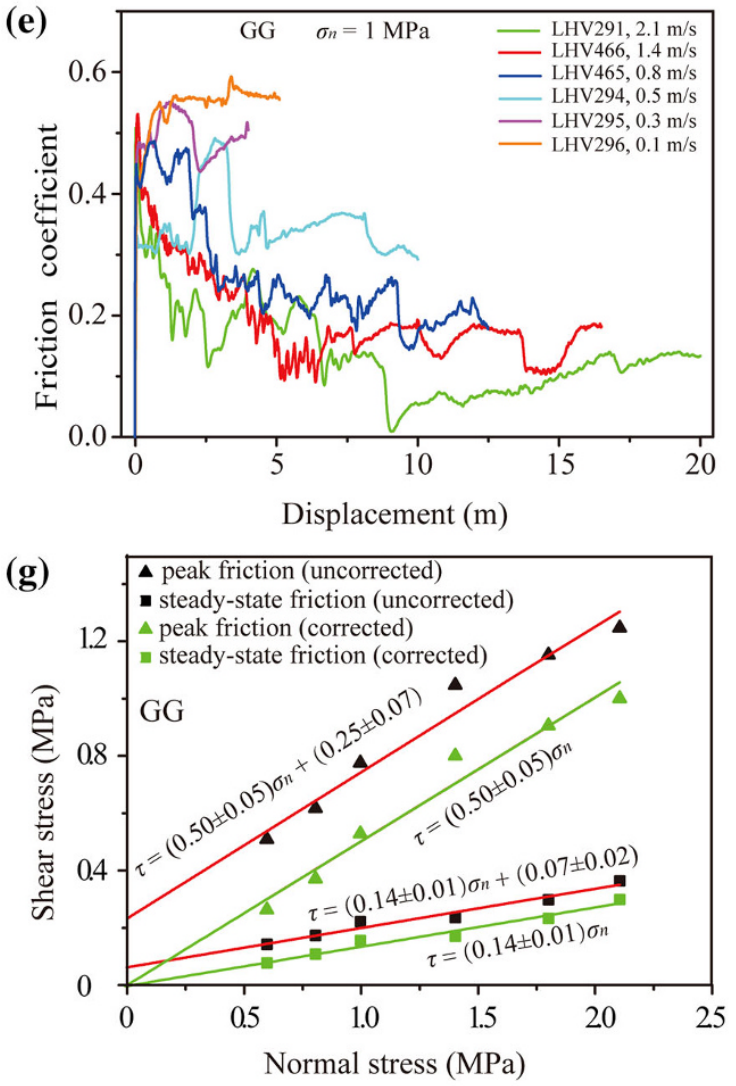

(b)

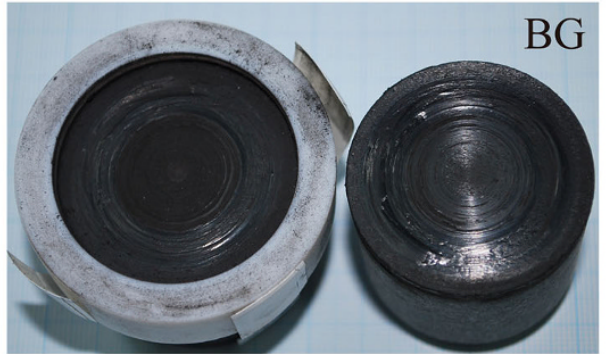

(d)

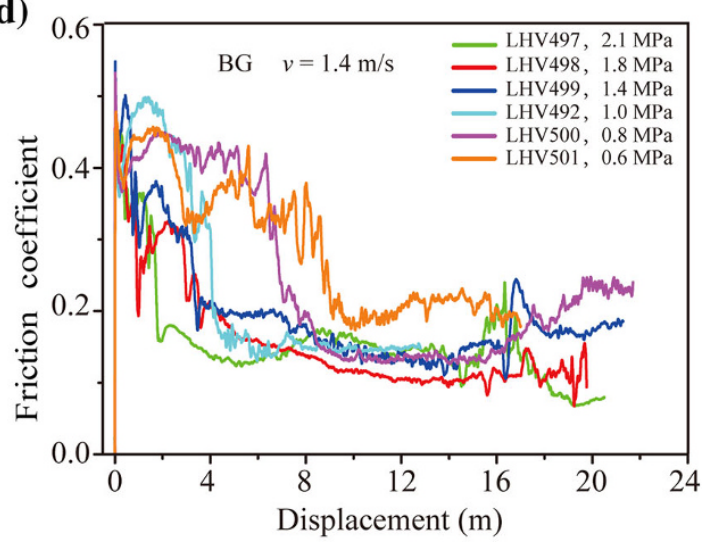

(f)
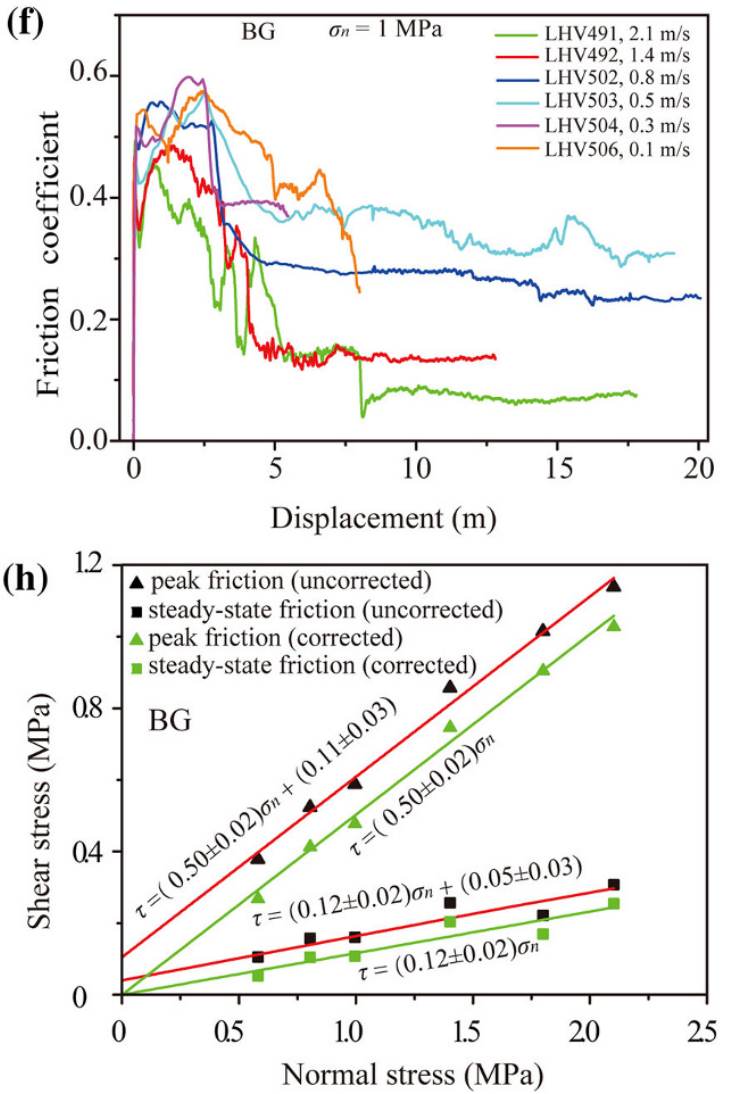

Fig. 9 a and b: Specimens with deformed grayish gouge (GG, run LHV465) and blackish gouge (BG, run LHV501), respectively. c-f: Friction coefficient versus displacement curves showing the normal stress and the slip-rate dependence of high-velocity frictional behaviors for GG (left side) and BG (right side). Slip rates and normal stresses for the experiments are given in the figures and listed in Table 1. $\mathbf{g}$ and $\mathbf{h}$ : Shear stress plotted against the normal stress for the peak friction (triangles) and steady-state friction (squares). Black and green symbols are before and after the correction of measured torque for the Teflon-upper specimen friction, respectively. Errors in coefficients are standard errors during the least-squares fitting with the Origin software 
(a)

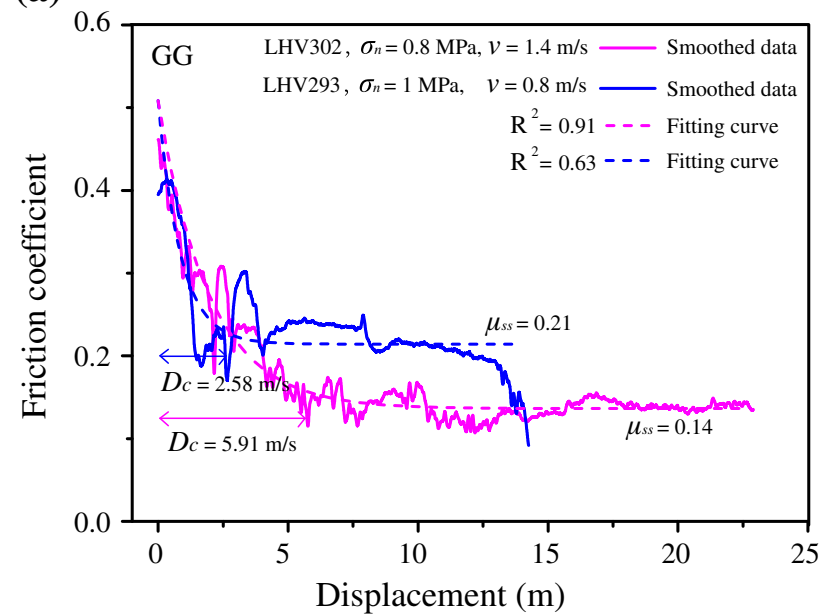

(b)

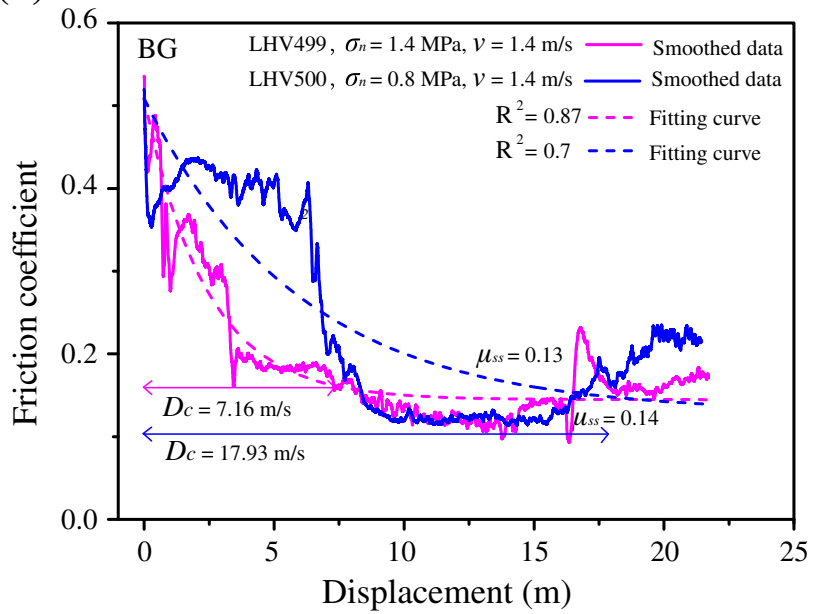

Fig. 10 A least-squares fitting (dashed curves) to four representative experimental results (solid curves) showing slip-weakening behaviors a on the grayish gouge (GG) and b on the blackish gouge (BG), with Eq. (1) using the Origin software. Results with pink and blue curves represent reasonably good and poor fittings, respectively (note the differences in the correlation coefficient R). Peak friction coefficient, $\mu_{\mathrm{p}}$, was taken as the maximum friction coefficient, and the steady-state friction coefficient $\mu_{\mathrm{ss}}$ and the slip-weakening distance $D_{\mathrm{c}}$ were determined by a leastsquares fitting as given in the diagrams

typical velocity range where a marked slip weakening begins to occur and getting good reproducibility of experiments is often difficult. Friction coefficient $\mu$ for GG at $v=0.5 \mathrm{~m} / \mathrm{s}$ drops abruptly from 0.49 to about 0.31 in about $0.1 \mathrm{~m}$ of slip, recovers to its near peak value at a displacement of about $3 \mathrm{~m}$, and then drops again to a level of 0.29-0.38 (LHV294 in Fig. 9e). But this rather strange behavior could be due to the gouge leakage. GG at $v=0.3$ and $0.1 \mathrm{~m} / \mathrm{s}$ exhibits gradual increase in $\mu$ toward near peak values of around $0.55-0.56$ at displacements $d$ of 1.4-1.5 m (LHV295 and LHV296 in Fig. 9e), and this initial increase in $\mu$ with increasing displacement is much slower than at seismic slip rates. After this, $\mu$ drops and then recovers at $v=0.3 \mathrm{~m} / \mathrm{s}$ (LHV295), but it stays at about the same level at $v=0.1 \mathrm{~m} / \mathrm{s}$ (LHV296). The slow increase in $\mu$ did not occur at $v=0.5 \mathrm{~m} / \mathrm{s}$ (LHV294, Fig. 11c), and $0.3-0.5 \mathrm{~m} / \mathrm{s}$ seems to be a boundary between abrupt drop and slow increase in friction toward the peak friction.

On the other hand, BG at $\sigma_{\mathrm{n}}=1 \mathrm{MPa}$ and $v=0.5-2.1 \mathrm{~m} / \mathrm{s}$ exhibits drop of the friction coefficient $\mu$ from its initial values of $0.45-0.50$ by $0.03-0.17$ during displacement $d$ of about $0.4 \mathrm{~m}$, gradual increase in $\mu$ toward the peak friction coefficient $\mu_{\mathrm{p}}$ of $0.45-0.58$ at $d=0.7-2.6 \mathrm{~m}$, then slip weakening toward steady-state friction coefficient $\mu_{\mathrm{ss}}$ of $0.06-0.3$ (four runs in Fig. 9f). Values of $\mu_{\mathrm{ss}}$ decrease with increasing $v$ (see slip-weakening parameters in Table 2). The initial drop in friction appears to be characteristics of BG at seismic slip rates. LHV504 and LHV506 at $v=0.3$ and $0.1 \mathrm{~m} / \mathrm{s}$ exhibit broad friction peaks with $\mu_{\mathrm{p}}$ of 0.60 and 0.57 followed by slip weakening, but displacements were not large enough in the runs to reach steady-state friction $\left(\mu_{\mathrm{ss}}\right.$ and $D_{\mathrm{c}}$ were not fit with the data; see Table 2).

\subsection{Results from slide-hold-slide (SHS) tests}

In a SHS test, the first sliding test was performed at a slip rate $v$ of $2.1 \mathrm{~m} / \mathrm{s}$ and a normal stress $\sigma_{\mathrm{n}}$ of $1.0 \mathrm{MPa}$ for about $7.5 \mathrm{~s}$, the servo-motor was stopped for a hold time $t_{\mathrm{h}}$ while keeping $\sigma_{\mathrm{n}}$ the same, and the second slide test was done at the same $v$ and $\sigma_{\mathrm{n}}$ for another $7.5 \mathrm{~s}$ (Fig. 11; Table 3). We conducted only one SHS test for a set of specimens because the gouge can change by processes such as mineral decompositions (e.g., Han et al. 2007a, b; Hirose and Bystricky 2007; Brantut et al. 2008). Both GG and BG show marked slip weakening during the first slide (Fig. 11a, c, respectively), with slip-weakening parameters listed in Table 3. Five tests were done at the same conditions for GG and BG with quite similar results, confirming good reproducibility of our high-velocity friction experiments. Slip-weakening parameters during the first slide (Table 3) give average slip-weakening parameters, $\mu_{\mathrm{p}}=0.41 \pm 0.01, \quad \mu_{\mathrm{ss}}=0.11 \pm 0.02$, and $D_{\mathrm{c}}=4.1 \pm$ 0.69 for $\mathrm{GG}$, and $\mu_{\mathrm{p}}=0.53 \pm 0.01, \mu_{\mathrm{ss}}=0.10 \pm 0.04$, and $D_{\mathrm{c}}=11.2 \pm 2.5$ for $\mathrm{BG}$, the errors being one standard deviation. The results are similar to those at the same conditions in Fig. 9e and f.

Hold time $t_{\mathrm{h}}$ was varied from 0.3 to $14,400 \mathrm{~s}$ as shown in Fig. $11 \mathrm{~b}$ and $\mathrm{d}$ for $\mathrm{GG}$ and $\mathrm{BG}$, respectively. For $t_{\mathrm{h}}=0.3 \mathrm{~s}$ (a very short hold time), the second peak friction 

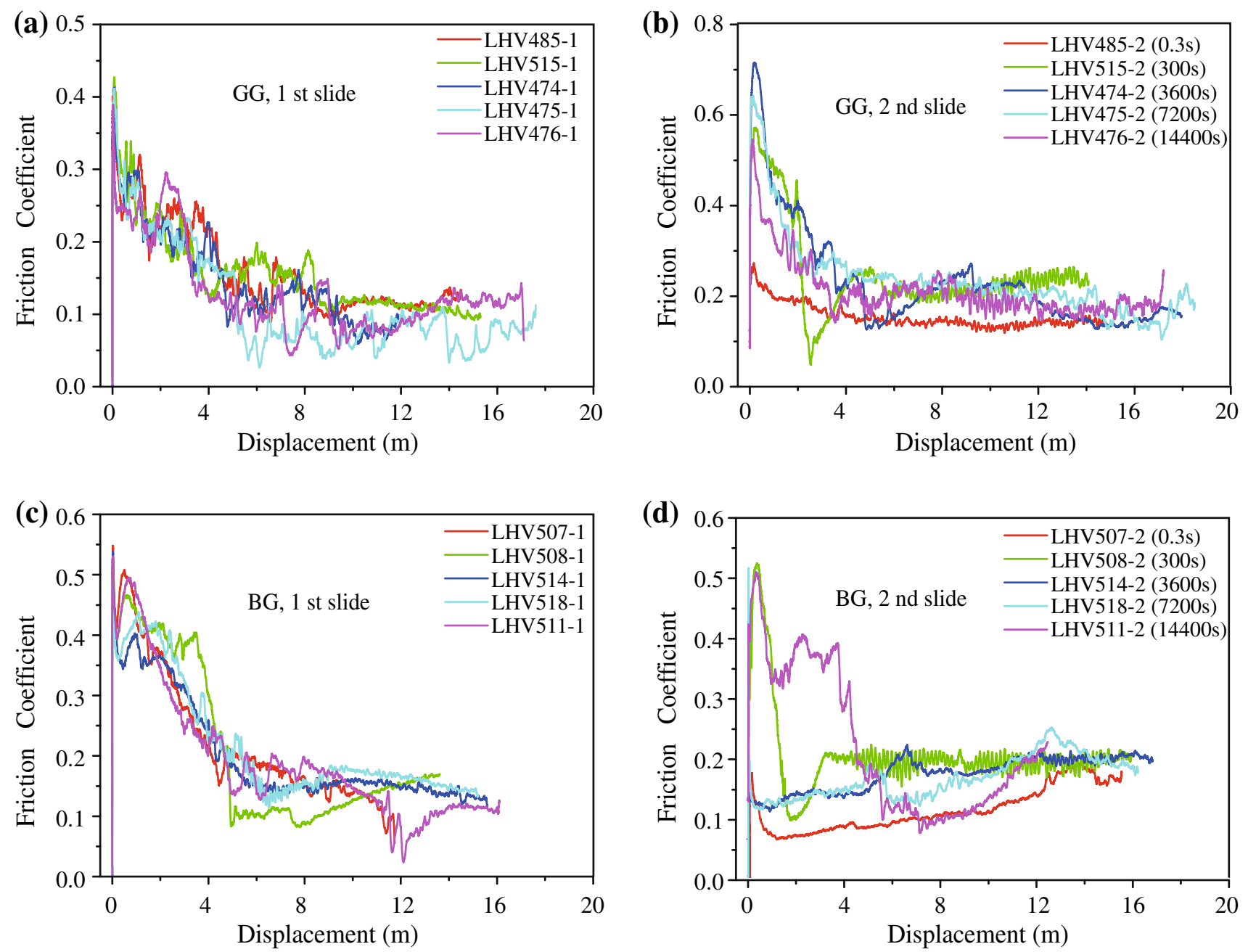

Fig. 11 Results from slide-hold-slide (SHS) tests conducted (a), (b) on grayish gouge (GG) and (c), (d) on blackish gouge (BG) at a normal stress $\sigma_{\mathrm{n}}$ of $1.0 \mathrm{MPa}$ and a slip rate $v$ of $2.1 \mathrm{~m} / \mathrm{s}$. Friction coefficient versus displacement curves for the first and the second slides are given on the left and right diagrams, respectively. Time given in parentheses following run numbers in (b) and (d) gives hold time in seconds. Sliding tests lasted for about $7.5 \mathrm{~s}$

coefficient, $\mu_{\mathrm{p}, 2 \text { nd }}$, is very small for both GG and BG indicating a small recovery of friction during the hold time. But $\mu_{\mathrm{p}, 2 \mathrm{nd}}$ increases with increasing $t_{\mathrm{h}}$ and becomes nearly equal or greater than the first peak friction coefficient at $t_{\mathrm{h}}=14,400 \mathrm{~s}$ (cf. Fig. 11a-d). We defined the recovery of friction during the hold time $(\Delta \mu)$ as $\left(\mu_{\mathrm{p}, 2 \mathrm{nd}}-\mu_{\mathrm{ss}, 1 \mathrm{st}}\right)$, where $\mu_{\mathrm{ss}, 1 \mathrm{st}}$ was determined by the least-squares fitting to the data during the first slide and $\mu_{\mathrm{p}, 2 \text { nd }}$ was taken as the initial peak friction coefficient during the second slide. Table 3 gives slip-weakening parameters and $\Delta \mu$. Friction can recover as much as $0.14-0.15$ in $0.3 \mathrm{~s}$ and $0.40-0.44$ in $300 \mathrm{~s}$ following seismic fault motion. GG exhibits slip weakening during the second slide, similar to those during the first slide (cf. Fig. 11a, b; see slip-weakening parameters in Table 3). However, the behaviors of BG during the second slide were more erratic than during the first slide, and we did not fit the results with Eq. (1).

\subsection{Comparison with data for other outcrops of Longmenshan fault zones}

We compare now the slip-weakening parameters and friction recovery in SHS tests, reported in the previous two subsections, with those reported for other outcrops of the Longmenshan fault system. Yao et al. (2013a) compiled slip-weakening parameters determined for fault gouge from several outcrops of the Longmenshan fault system (reproduced here as Fig. 12a-c; samples S1-S6 are listed at the bottom of the figure caption). S1 and S2 are from Bajiao Miao, Hongkou outcrop of the Yingxiu-Beichuan fault zone formed in Triassic shale, siltstone and sandstone and this is the drilling sites of WFSD-1 and 2 (Li et al. 2013, 2014). S1 was taken from a gouge zone close to the coseismic slip zone during the Wenchuan earthquake (Togo et al. 2011a, 2011b), and S2 was collected from a 
gouge zone of about $4 \mathrm{~m}$ in width at a middle part of the fault zone (Yao et al. 2012). S3 is sample from a smallscale bedding-parallel fault zone in limestone at Xiaojiaqiao, a subsidiary fault of the Yingxiu-Beichuan fault (Hou et al. 2012). S4 was sampled from Zhaojiagou outcrop at a middle part of the Yingxiu-Beichuan fault zone with carbonates on the northwest side and shale and sandstone on the southeast side (Chen et al. 2013a, 2013c). S5 and S6 are yellowish and gray-blackish gouge samples, respectively, collected from the Kuangpingzi outcrop of Pingxi fault zone in sandstone, shale, siltstone, and carbonates (Yao et al. 2013a). This outcrop is close to the northeastern end of the coseismic surface ruptures. We plotted our results in Fig. 12a-c as S7 for GG and S8 for BG. Overall samples cover western, central, and eastern parts of the coseismic faults during the Wenchuan earthquake.

The peak friction coefficient $\mu_{\mathrm{p}}$ is $0.6-0.9$ for S1-S6, but GG and BG (S7 and S8) from the Shenxigou fault zone have $\mu_{\mathrm{p}}$ of around 0.4-0.6, smaller than that for other samples (Fig. 12a), whereas the steady-state friction coefficient $\mu_{\mathrm{ss}}$ for $\mathrm{GG}$ and $\mathrm{BG}$ are consistent with reported values shown in small triangles. Yao et al. (2013a) fit the data for $\mu_{\mathrm{ss}}$ with the following equation, simplified from an equation proposed by Sone and Shimamoto (2009):

$\mu_{\mathrm{ss}}(v)=\mu_{\mathrm{ss}}^{\infty}+\left(\mu_{\mathrm{ss}}^{0}-\mu_{\mathrm{ss}}^{\infty}\right) \exp \left(-v / V_{\mathrm{ss}}^{\mathrm{c}}\right)$,

where $\mu_{\mathrm{ss}}^{0}$ and $\mu_{\mathrm{ss}}^{\infty}$ are the peak and steady-state friction coefficients at zero and infinitely large slip rates, respectively, and $V_{\mathrm{ss}}^{\mathrm{c}}$ is the critical weakening velocity at which $\left(\mu_{\mathrm{ss}}(v)-\mu_{\mathrm{ss}}^{\infty}\right)$ reduces to $\left(\mu_{\mathrm{ss}}^{0}-\mu_{\mathrm{ss}}^{\infty}\right) / e$. The equation cannot describe the velocity dependence of friction at slow slip rates (e.g., $1 \mathrm{~mm} / \mathrm{s}$ ) and has been used to describe the weakening at high slip rates (De Paola et al. 2011; Togo et al. 2011b). The least-squares fitting for the all data on S1-S8 gives $\mu_{\mathrm{ss}}^{0}=0.98 \pm 0.05, \mu_{\mathrm{ss}}^{\infty}=0.13 \pm 0.02$, and $V_{\mathrm{ss}}^{c}=0.38 \pm 0.05$ (thick yellow curve in Fig. 12a) which are nearly the same as those for S1-S6 $\left(\mu_{\mathrm{ss}}^{0}=0.74 \pm 0.03\right.$, $\mu_{\mathrm{ss}}^{\infty}=0.13 \pm 0.02$, and $\left.V_{\mathrm{ss}}^{c}=0.37 \pm 0.05\right)$ determined by Yao et al. (2013a, Table 3).

The slip-weakening distance $D_{\mathrm{c}}$ decreases with increasing normal stress $\sigma_{\mathrm{n}}$ (Fig. 12b) and with increasing slip rate $v$ (Fig. 12c), as recognized previously (Di Toro et al. 2011; references therein). $D_{\mathrm{c}}$ values for BG from Shenxigou fault zone are plotted slightly higher than those for other outcrops of the Longmenshan fault zones, but those for GG are consistent with the other outcrop data. $D_{\mathrm{c}}$ can be described by an empirical equation (modified from Togo et al. (2011b) for the dimensional consistency):

$D_{\mathrm{c}}=A\left(\sigma_{\mathrm{n}} / \sigma_{\mathrm{r}}\right)^{-B}\left(v / v_{\mathrm{r}}\right)^{-D}$,

where $A, B$, and $C$ are constants, and $\sigma_{\mathrm{r}}$ and $v_{\mathrm{r}}$ are reference normal stress and reference slip rate, respectively. The least-squares fitting for all data, S1-S8, yields $A=9.24 \pm 0.49 \mathrm{~m}, B=1.43 \pm 0.12$, and $C=0.48 \pm$ 0.11 with $\sigma_{\mathrm{r}}=1 \mathrm{MPa}$ and $v_{\mathrm{r}}=1 \mathrm{~m} / \mathrm{s}$ (thick yellow curves in Fig. 12b, c). Those values are close to the values for S1S6 $(A=9.11 \pm 0.47 \mathrm{~m}, \quad B=1.55 \pm 0.10$ and $C=$ $0.51 \pm 0.10$ ), and the Shenxigou fault gouges have very similar properties with respect to the high-velocity frictional properties.

Figure 12d shows a comparison of our results from SHS tests in Fig. 11 with those for Pingxi gouge (S5 and S6) by Yao et al. (2013b). Experimental procedures were exactly the same except that $\sigma_{\mathrm{n}}$ and $v$ were $1.0 \mathrm{MPa}$ and $2.1 \mathrm{~m} / \mathrm{s}$ in our tests, whereas those were $0.8 \mathrm{MPa}$ and $1.4 \mathrm{~m} / \mathrm{s}$ in their experiments, respectively. Yao et al. (2013b) recognized very rapid recovery of frictional strength in proportion to the logarithm of hold time $t_{\mathrm{h}}$ (as much as about 0.4 in friction coefficient) in about $10 \mathrm{~s}$, in association with the very rapid cooling of fault zone (Fig. 12d). But the rate of recovery declines after this, and the slope of $\Delta \mu$ versus log $\left(t_{\mathrm{h}}\right)$ relationship becomes nearly the same as those determined in the traditional SHS tests at low slip rates (Yao et al. 2013b, Fig. 8 and references therein). Our results for GG and BG, plotted with green and pink circles in Fig. 12d, are not enough to delineate the trend, but are consistent with the results of Yao et al. (2013b).

\section{Microstructures of deformed fault gouge}

Yao et al. (2013a, 2013b) report scanning electron microscope (SEM) microstructures of three types of gouge from the Pingxi fault zone, Longmenshan fault system, deformed at high velocities using the same apparatus used in this study. We used the same field-emission environmental SEM (FEI Quanta 200F) at the Microstructure Laboratory for Energy Materials, China University of Petroleum, as in their observations. Observations were made on gold-coated thin sections of deformed gouge samples, impregnated with the Struers' Specifix 40. Thin sections were made normal to the sliding surface at a position between the cylindrical axis and the margin of the specimens so the shear textures can be seen in the central part. All photomicrographs in Figs. 13 and 14 are backscattered electron images, taken under an acceleration voltage of $50 \mathrm{kV}$. All photographs are arranged with the moving block on the top side with right-lateral sense of shear as shown by a pair of arrows. Note that black zones mostly in horizontal directions in Figs. 13 and 14 are Specifix 40 filling open cracks during the processes making thin sections. We have confirmed the presence of quartz, plagioclase, and carbonate clasts using an energy dispersive X-ray spectrometer (EDS) attached to the FE-SEM. 

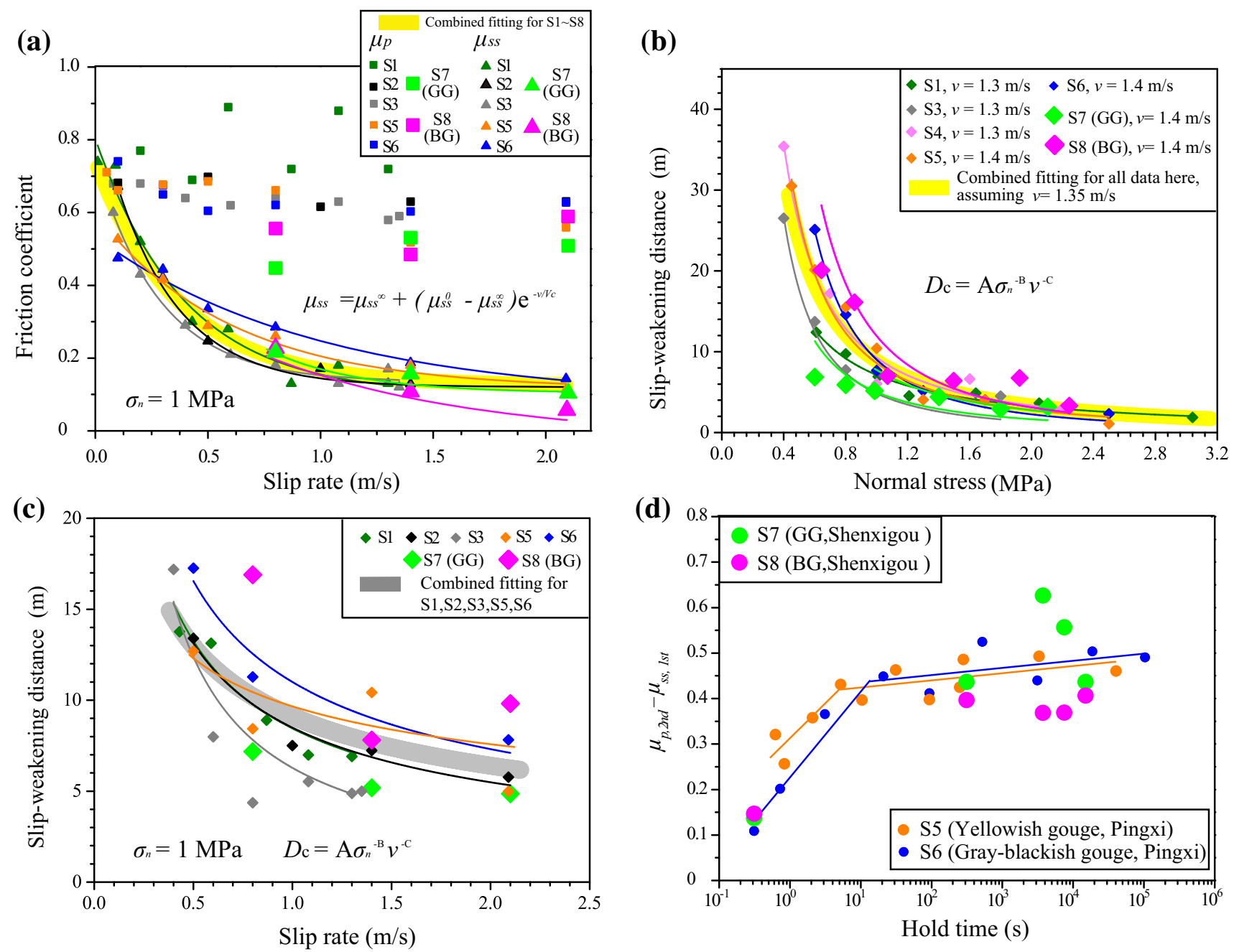

Fig. 12 Comparison of a-c slip-weakening parameters and $\mathbf{d}$ recovery of friction during the SHS tests from this study with those for other outcrops of the Longmenshan fault zones (localities and gouge types given at the end of this caption). We plotted out data on diagrams of Yao et al. (2013a, b). a exhibits the peak friction coefficient ( $\mu_{\mathrm{p}}$, squares) and steady-state friction coefficients $\left(\mu_{\mathrm{ss}}\right.$, triangles) plotted against the slip rate, $\mathbf{b}$ and $\mathbf{c}$ show the slip-weakening distance $D_{\mathrm{c}}$ plotted against the normal stresses $\sigma_{\mathrm{n}}$ and slip rate $v$, respectively. $\mathbf{d}$ gives an increase in the frictional coefficient from the friction coefficient at the end of the first slide, $\mu_{\mathrm{ss}, 1 \mathrm{st}}$, to the peak friction coefficient during the second slide, $\mu_{\mathrm{p}, 2 \mathrm{nd}}$, plotted against the logarithm of the hold time. Thin lines and broad yellow lines in $\mathbf{a}$ and $\mathbf{b}$ are the least-squares fit with Eqs. (2) and (3) for each outcrop data and for the whole data including our results, respectively. The orange and blue lines in (d) are the least-squares fitting to the yellowish and blackish gouges, respectively, from Pingxi fault zone after Yao et al. (2013b). Normal stress $\left(\sigma_{\mathrm{n}}=1 \mathrm{MPa}\right)$ in (a) and (c) applies only to GG and BG from this study. S1 Fault gouge close to coseismic slip zone of the Yingxiu-Beichuan fault zone at Bajiao Miao, Hongkou (Togo et al. 2011b) S2 Fault gouge from a middle part of the Yingxiu-Beichuan fault zone at Bajiao Miao, Hongkou (Yao et al. 2012). S3 Fault gouge from Xiaojiaqiao outcrop of a small-scale fault zone (Hou et al. 2012) S4 Fault breccia from Zhaojiagou outcrop of the Yingxiu-Beichuan fault zone (Chen et al. 2013c) S5 Yellowish fault gouge from Kuangpingzi outcrop of Pingxi fault zone (Yao et al. 2013a, b) S6 Gray-blackish fault gouge from Kuangpingzi outcrop of Pingxi fault zone (Yao et al., 2013a, b) GG (S7): Gray gouge from Shenxigou outcrop (this study) BG (S8): Black gouge from Shenxigou outcrop (this study)

But clay minerals were too fine-grained to be identified by the EDS chemical analysis.

\subsection{Grayish black gouge $(\mathrm{GG})$}

We selected three gouge samples deformed at normal stresses $\sigma_{\mathrm{n}}$ of 0.8 and $1.0 \mathrm{MPa}$ and at slip rates $v$ of 0.3 and $1.4 \mathrm{~m} / \mathrm{s}$ as representative examples of deformed GG.
Gouge deformed at a normal $\sigma_{\mathrm{n}}=1 \mathrm{MPa}$ and a slip rate of $v=1.4 \mathrm{~m} / \mathrm{s} \quad$ (LHV292) is characterized by highly deformed zones at both upper and lower boundaries with the host rocks and by weakly deformed gouge in the interior (Fig. 13a). Weakly deformed gouge contains clasts of about $100 \mu \mathrm{m}$ in size, close to the upper limit of gouge particles $(150 \mu \mathrm{m})$. Thin fractures such as AB in Fig. 13a formed in the weakly deformed gouge zone in the direction 

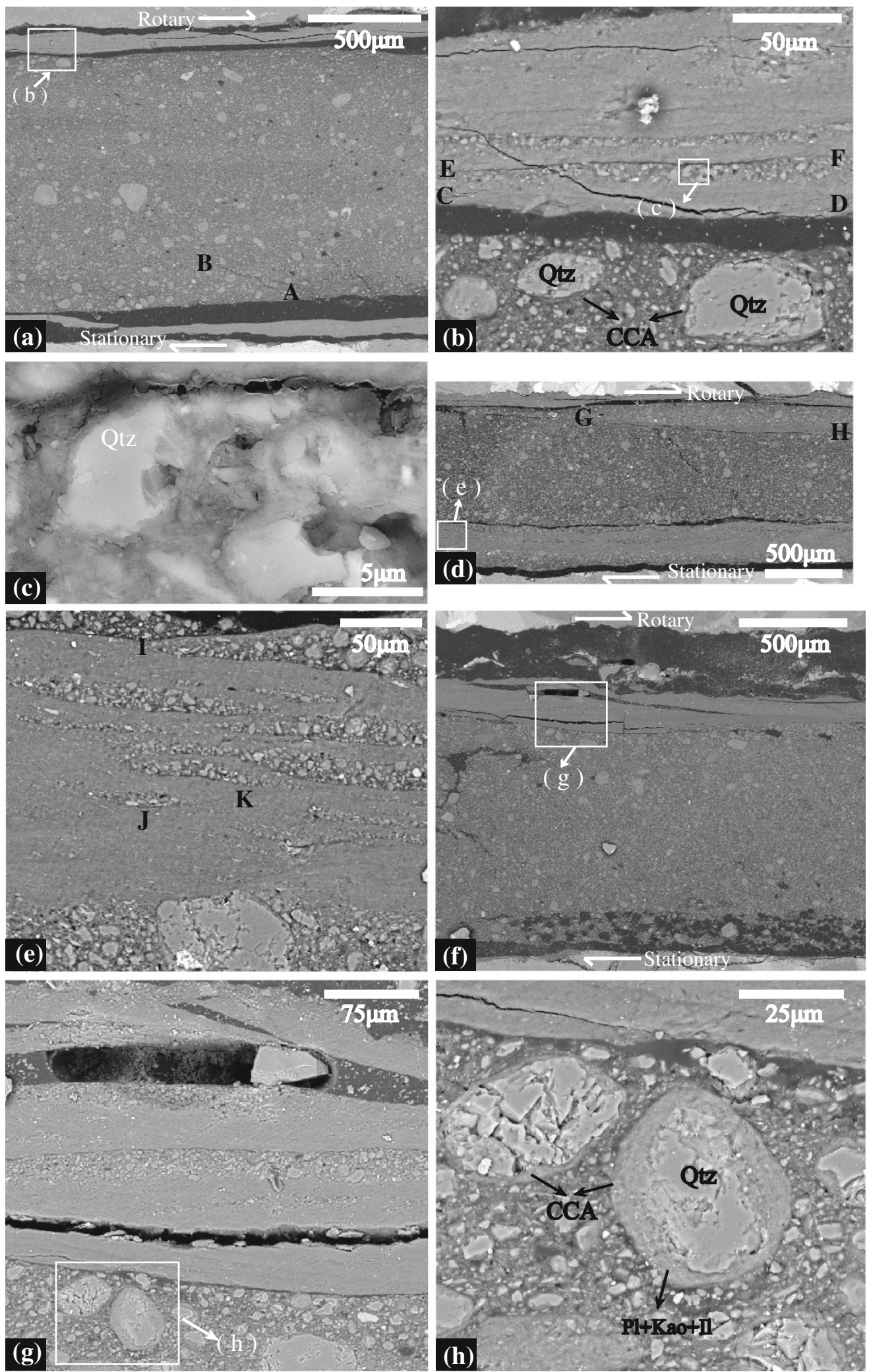

Fig. 13 Back-scattered electron images of the grayish gouge (GG) deformed (a) $-(\mathbf{c})$ at a normal stress $\sigma_{\mathrm{n}}=1 \mathrm{MPa}$ and a slip rate $v=1.4 \mathrm{~m} / \mathrm{s}$ (LHV292), (d) and (e) at $\sigma_{\mathrm{n}}=1 \mathrm{MPa}$ and $v=0.3 \mathrm{~m} / \mathrm{s}\left(\right.$ LHV295), and (f) $-(\mathbf{h})$ at $\sigma_{\mathrm{n}}=0.8 \mathrm{MPa}$ and $v=1.4 \mathrm{~m} / \mathrm{s}$ (LHV302). (b), (c), (e), (g), and (h) show close-up photomicrographs of the rectangular portions in (a), (b), (d), (f), and (g), respectively. All photomicrographs in this and next figure were taken with a field-emission environmental SEM at the Microstructure Laboratory for Energy Materials, China University of Petroleum. Abbreviations: $Q t z$ quartz, $C C A$ clay-clast aggregate 

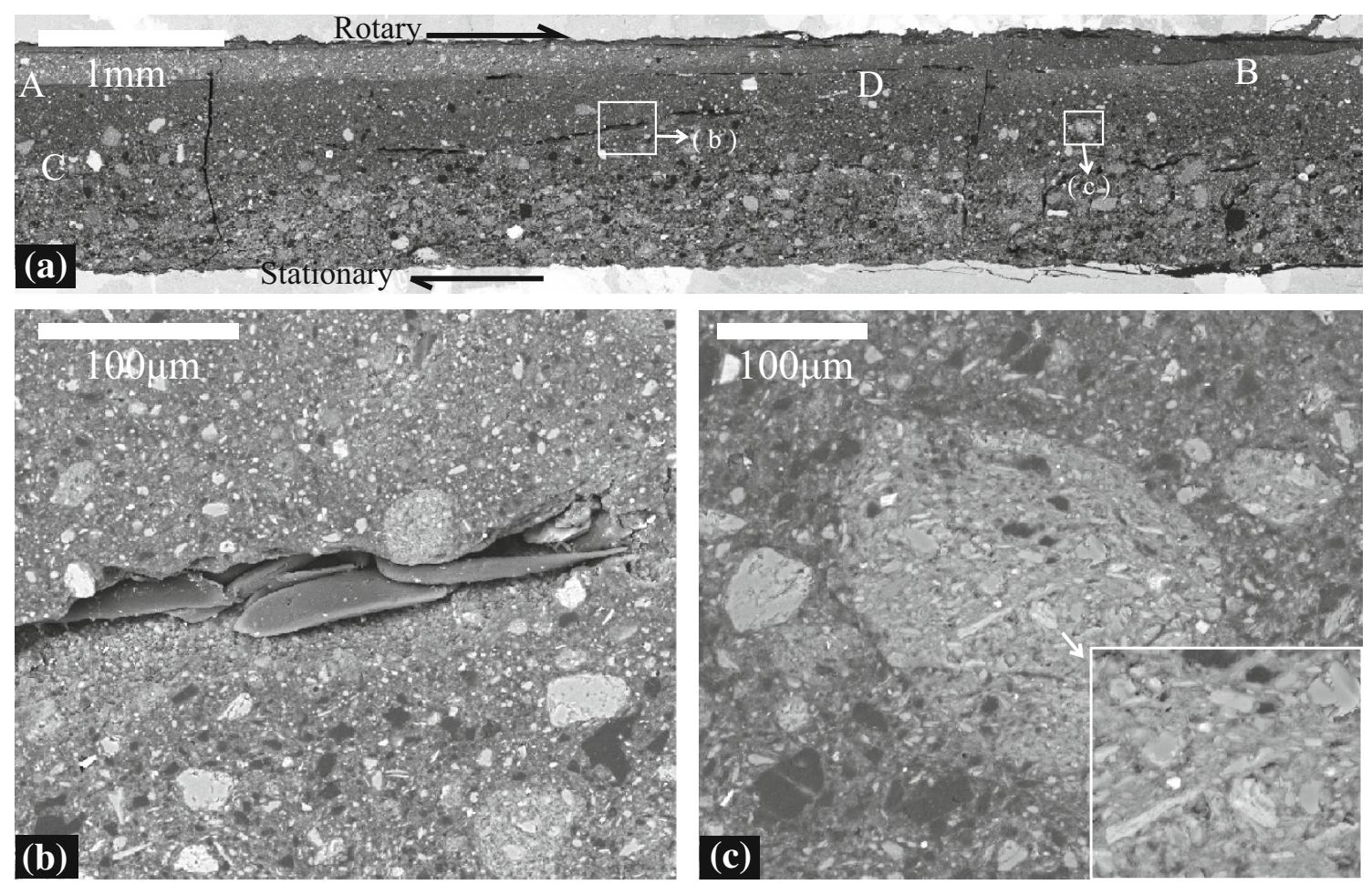

Fig. 14 Back-scattered electron images of the blackish gouge (BG) deformed at a normal stress $\sigma_{\mathrm{n}}=0.8 \mathrm{MPa}$ and a slip rate $v=1.4 \mathrm{~m} / \mathrm{s}$ (LHV500)

of $\mathrm{R}_{1}$ Riedel shear (e.g., Bartlett et al. 1981; Logan et al. 1992). Clay-clast aggregates (CCA; Boutareaud et al. 2010) formed in the weakly deformed gouge as shown by three CCA's around quartz grains in Fig. 13b, a close-up of the rectangular portion in Fig. 13a. Multiple deformed zones are developed in each highly deformed zone with horizontal banding. CDEF in Fig. 13b is an example of such a deformed zone, consisting of an ultrafine-grained zone along $\mathrm{CD}$ with particles mostly less than $1 \mu \mathrm{m}$ in size which gradually changes to coarse-grained zone along EF. Changes in grain size below the ultrafine-grained zone CD and above the coarse-grained zone EF are sharp. Very similar textures were reported previously (Togo and Shimamoto 2012; Sawai et al. 2012; Yao et al. 2013a, 2013b), and as in those papers, we interpret those ultrafine-grained zones as slip zones where particles were crushed down to nanometer sizes due to extreme shearing deformation associated with fault displacement. An interesting point is that the ultrafine-grained and coarse-grained zones appear to have behaved as a unit, and Togo and Shimamoto (2012) reported sintered or welded grains in the coarse-grained zones. We recognized similar welded or sintered grains with only a few pores left in the zone in Fig. 13c, a closeup of rectangular portion in Fig. 13b. There are two pores near the center of Fig. 13c, similar to pores that have been interpreted as the escape holes of dehydrated water or gas due to mineral decomposition (e.g., Yao et al. 2013a).
Three deformed zones formed at the upper gouge-rock boundary, at a lower horizontal portion of gouge close to the lower gouge-rock interface, and along a branched zone from G toward $\mathrm{H}$ in GG deformed at $\sigma_{\mathrm{n}}=1 \mathrm{MPa}$ and $v=0.3 \mathrm{~m} /$ s (LHV295, Fig. 13d). Gouge zone in the center, a thin gouge zone above $\mathrm{GH}$, and the lower part of gouge adjacent to the stationary host rock remain weakly deformed. Multiple slip zones developed in the directions of $R_{1}, Y$, and $P$ Riedel shears, as shown in Fig. 13e (close-up of rectangular portion in Fig. 13d). A cross-cutting relationship is recognized at I where a slip zone in a direction of Y Riedel shear is cut by a slip zone in $R_{1}$ direction. At points $J$ and $K$ in Fig. 13e, slip zones in $R_{1}$ directions are cut by a slip zone in a $\mathrm{P}$ direction. In the last example of GG deformed at $\sigma_{\mathrm{n}}=0.8 \mathrm{MPa}$ and $v=1.4 \mathrm{~m} / \mathrm{s}$ (LHV302), a highly deformed zone formed at the upper gouge-host rock interface (Fig. 13f) with a very clear asymmetric grain-size distributions (Fig. 13g, a close-up of rectangular portion in Fig. 13f). CCA's formed around quartz grains in weakly deformed gouge below the highly deformed zone (Fig. 13h, a close of rectangle in Fig. 13g). The overlapped slip-zone structures with cross-cutting relationships in deformed GG strongly suggest that the structures form as a result of shift of slip zones and complex deformation of old slip zones. Clear and shiny slickenside surface probably did not form in deformed GG probably because of more complex and diffused deformation than BG (see Fig. 9a). 


\subsection{Blackish gouge (BG)}

In marked contrast with GG, overlapped slip-zone structures did not form in deformed BG, as shown in a representative example of $\mathrm{BG}$ deformed at $\sigma_{\mathrm{n}}=0.8 \mathrm{MPa}$ and $v=1.4 \mathrm{~m} / \mathrm{s}$ (LHV500, Fig. 14). Deformed BG is characterized by ultrafine-grained slip zones, moderately deformed gouge zone (roughly upper $60 \%$ of gouge), and weakly deformed gouge (about lower $40 \%$ of gouge). The boundary between moderately and weakly deformed gouge zones is gradual (Fig. 14a), but the boundary between moderately deformed gouge and highly sheared slip zone is quite sharp and distinct (Fig. 14b). Slip zones are only a few microns thick or even less and formed along the upper gouge-rock interface, along $\mathrm{AB}$ subparallel to the upper interface, and along a slightly cone-shaped surface $\mathrm{CD}$ in Fig. 14a; see a close-up of a slip zone in Fig. 14b. Clasts of around $100 \mu \mathrm{m}$ in size are scattered in moderately to weakly deformed gouge zones (Fig. 14a), but many grainlike particles are aggregates of fine particles as shown in an example of Fig. 14c (see a close-up photomicrograph in the inset frame). A very sharp slip zone of BG at gouge-rock interface correlates with a shiny, beautiful slickenside surface of deformed BG in Fig. 9b.

\section{Discussion}

6.1 Fault zone structures and its implications for paleoearthquakes

Outcrop studies (Figs. 2c, 3), a trench survey of coseismic fault during the 2008 Wenchuan earthquake (Fig. 4), and a shallow drilling into the coseismic fault (Figs. 5 and 6) have revealed that the fault zone in Shenxigou formed in Triassic sedimentary rocks and is $250-300 \mathrm{~m}$ wide consisting of about $0.5 \mathrm{~m}$ thick gouge close to the coseismic fault and mostly fault breccia. A few gouge zones were recognized in drill cores and on surface outcrops, but gouge zones are not abundant although fault-zone outcrops do not cover the whole fault zone. We have not confirmed the northwestern boundary of the fault zone with host rocks yet. However, thick conglomerate in the Triassic formation forms waterfalls and cliffs at a northwestern part of the surveyed area in Fig. 2c, and the fault zone in Shenxigou is not a part of the Yingxiu-Beichuan fault zone (Figs. 1a, 2a).

The shallow drilling indicates that the coseismic fault is dipping to the northwest by $68^{\circ}$ (Fig. 6c), consistent with steeply dipping coseismic faults during the Wenchuan earthquake (e.g., Zhang et al. 2010; Zhang 2013a). The drilling also revealed that the fault zone thrust over Quaternary conglomerates at least by $55 \mathrm{~m}$ forming $1-2$ meter- thick fault breccia zone of the Quaternary conglomerates (Fig. 5). The vertical offset during the Wenchuan earthquake was $2.8 \mathrm{~m} \mathrm{(3.0} \mathrm{m} \mathrm{in} \mathrm{vertical} \mathrm{displacement),} \mathrm{so} \mathrm{that}$ the fault must have experienced about 18 earthquakes similar to the Wenchuan earthquake. An average recurrence interval of earthquakes will be estimated if the age of soil in the conglomerates (e.g., Fig. $6 \mathrm{~g}$ ) can be measured. If the recurrence interval is on the order of 3,000 years as suggested by Ran et al. (2010) and Zhang (2013b), the age may be close to the limit of ${ }^{14} \mathrm{C}$ dating. Shenxigou valley near the displaced and tilted roads (Fig. 3a, b) was flat before the Wenchuan earthquake. Paleoseismic events can be detected through the study of the conglomerate if the low land below the fault scarp is filled up rapidly following an earthquake. Thus, the drilling into the Quaternary conglomerate parallel to the coseismic fault in Fig. 6h will provide interesting data for paleoseismic events along this fault (a very important task for the future).

Lin et al. (2010) reported that the fault zone (southwestern wall of the same trench as described here) consisted of a fault core that includes a narrow fault gouge zone $<150 \mathrm{~mm}$ in width and a fault breccia zone $<3 \mathrm{~m}$ in width, and a wide damage zone $>5 \mathrm{~m}$ in width that is composed of cataclastic rocks. The width of gouge zone is not consistent with our result and we did not confirm any cataclasites at the trench wall and in drill cores. Gouge zone next to the coseismic fault during the Wenchuan earthquake is 400-700 mm wide at the trench walls of the coseismic fault (Fig. 4) and is about $300 \mathrm{~mm}$ wide in the drill core (Fig. 5). The mixing of gouge from the Triassic formation into the fault breccia of Quaternary conglomerate (Fig. 6f) suggests that tectonic erosion of fault gouge took place as the wide fault zone thrust over the conglomerate, and this is probably a reason why the gouge zone next to the coseismic fault is not so thick. The gouge zone consists of GG and BG, which were severely deformed to form foliated and folded fault gouge with cross-cutting relationships, roughly in half of the gouge zone close to the coseismic fault (Fig. 7d-f). GG contains quartz, plagioclase, illitesmectite mixed layer clays, and illite, whereas BG consists of quartz, plagioclase, carbonates, illite-smectite mixed layer clays, illite, and chlorite (Table 1). BG and blackish fault breccia contains about $28 \%$ and $36 \%$ of organic carbon, but GG and grayish fault breccia (S1) are nearly free from carbonaceous materials (samples SXG-BG and S2 in Table 1; Fig. 8). The mineral compositions of samples given in Table 1 have to be subtracted by the amounts of carbonaceous materials.

Graphite has friction coefficient of about 0.1 at low to high slip rates and has received increasing attention recently as a possible lubricant in fault zones (Oohashi et al. 2011, 2013; references therein). Oohashi et al. (2012) report graphite up to $12 \%$ in Atotsugawa fault zone in 
Japan, enough amount to reduce friction under extremely large shearing deformation (Oohashi et al. 2013). The contents $(\sim 30 \%)$ of carbonaceous materials in BG and blackish fault breccia are much greater than the graphite contents in Atotsugawa fault zone, but the carbonaceous materials in Shenxigou were low-crystalline graphite, not fully crystallized graphite (Fig. 8e, f). Low-velocity frictional properties, compared with the graphite friction, and possible shear-induced graphitization (e.g., Oohashi et al. 2011) have to be studied in the future using the low-crystalline graphite from Shenxigou, in order to evaluate the importance of such a large amount of low-crystalline graphite on the frictional properties of fault zone. BG and GG occupy matrix and clasts, respectively, when they coexist (Fig. 7b). The carbon-rich matrix might have formed by solution-precipitation processes, i.e., by the removal of soluble minerals such as quartz with water flow through fault rocks and resulting enrichment in insoluble carbonaceous materials, as proposed by Oohashi et al. (2012). Carbonaceous materials in BG and in Triassic sedimentary rocks have nearly the same isotope composition $\delta^{13} \mathrm{C}$ of 24-25\% (J. Chen, unpublished data), which corresponds to the composition of the organic carbon in sedimentary rocks (e.g., Hoefs 2004, Fig. 21). Thus, the isotopic compositions are consistent with the enrichment mechanism of carbon via pressure solution. However, how localized enrichment of carbon occurred in the Shenxigou fault zone remains uncertain. Carbonaceous materials in BG filling fractures (Figs. 4d, 7c) might have formed as a precipitation from carbon-rich fluid, another mechanisms suggested by Oohashi et al. (2012). However, the isotopic compositions of carbon in $\mathrm{BG}$ and host rocks will be a constraint in considering the precipitation processes in more detail. High carbon content in blackish fault breccia indicates that a seismic slip is not required to form carbon in the Shenxigou fault zone. We plan to explore the origin of carbon in Shenxigou in the future.

\subsection{Fault zones from Bajiao Miao, Hongkou to Shenxigou}

The Yingxiu-Beichuan fault zone at Bajiao Miao, Hongkou is the best studied fault zone in the Longmenshan fault system, following the Wenchuan earthquake. LiuZeng et al. (2010) described and discussed the overlapped striations on a beautiful slickenside surface of the coseismic fault at this outcrop. Lin et al. (2010) originally reported a several-meter wide fault zone including the coseismic fault. However, a debris flow excavated fault zone of about 30-40 m in width behind the coseismic fault, as described in detail by Togo et al. (2011a). However, they could not enter into the restricted area further to the north and described only the southeastern part of the fault zone. Most complete descriptions of the entire fault zone so far are reported by Li et al. $(2013,2014)$ and Wang et al. (2014) based on WFSD-1 drill holes and surface outcrops, revealing a fault zone of about $100 \mathrm{~m}$ in width. The fault zone at Bajiao Miao is a part of Yingxiu-Beichuan fault zone at the boundary of the Proterozoic Pengguan Massif and Triassic sedimentary rocks. Cataclasite-bearing cohesive fault rocks of about $10 \mathrm{~m}$ in core interval formed at the margin of the Pengguan Massif, about 30 gouge zones formed in about two-third of the fault zone in the Triassic formation on the northwestern side, and about one-third of the fault zone on the southeastern side consists of a wide fault breccia zone and a few gouge zones (Li et al. 2013, Fig. 8). Fault motion during the Wenchuan earthquake occurred at the southeastern margin of the fault zone and it appears that the location of active movement jumped to the southeastern front of the fault zone. Quaternary conglomerate to the southeast side of the coseismic fault was not recognized in WFSD-1 hole below a depth of $759 \mathrm{~m}$ where the wide fault zone was adjacent to the Triassic host rocks, mostly sandstones (Li et al. 2013, Fig. 4). The southeastern boundary of fault zone dips at about $70^{\circ}$ to $\mathrm{NW}$ at this outcrop (Li et al. 2013, Fig. 17), so that distance along the fault from a depth of $759 \mathrm{~m}$ to the surface is $808 \mathrm{~m}$. Thus, about $800 \mathrm{~m}$ is the maximum vertical displacement after the shift of fault motion to the southeastern boundary of the fault zone because the Quaternary conglomerates did not exist below the fault zone in the drill cores. Li et al. (2013) proposed that the coseismic slip during the Wenchuan earthquake occurred close to the northwestern margin of the incohesive fault zone (Li et al. 2013, Fig. 17). Such a diagonal fault motion across a wide fault zone will lead to an uneven distribution of fault width, but the fault zone is of about the same widths between the surface and drilling depths of WFSD-1.

It is of interest to compare fault zones in Shenxigou and Bajiao Miao, Hongkou. The dipping angles of faults are very similar; $68^{\circ}$ as revealed by our shallow drilling $(57 \mathrm{~m})$ versus $70^{\circ}$ determined from WFSD-1. Recent fault displacement of at least $55 \mathrm{~m}$ occurred along the coseismic fault in Shenxigou, whereas the total recent movement along the coseismic fault at Bajiao Miao over the Quaternary conglomerate is not determined, although it is less than about $800 \mathrm{~m}$. The fault zone in Shenxigou is 250-300 m wide and is much wider than that at Bajiao Miao (ca. $100 \mathrm{~m}$ ). Cataclasites and many gouge zones on the northwestern side of the fault zone in Bajiao Miao were not found in Shenxigou, although outcrop information in the latter is far incomplete than in nearly continuous WFSD-1 drill cores. We have not found the contact of the wide fault zone and host rock on the northwestern side as yet. However, there is a thick conglomerate rocks forming a series of waterfalls and cliffs between the fault zone and 
the Pengguan Massif (Fig. 2c), and the fault zone in Shenxigou definitely is not a part of Yingxiu-Beichuan fault. It seems that the coseismic surface ruptures during the Wenchuan earthquake gradually deviate from the Yingxiu-Beichuan fault in Hongkou and approaches toward Xuankou fault as demonstrated clearly by Liu-Zeng et al. (2010) (see Fig. 1). The lack of cataclasites and many gouge zones in the Shenxigou fault zone implies that the coseismic faults from Bajiao Miao to Shenxigou, mapped by Liu-Zeng et al. (2010), formed after shifting of fault movement to the southeastern boundary of fault zone in Bajiao Miao. This fault should be named as "HongkouShenxigou fault" since no faults are drawn along the coseismic faults in geological map (Sichuan Bureau of Chinese Geological Survey 1976). But detailed field work on the distributions of fault zones and their internal structures needs to be carried out to clarify the nature and evolution of fault zones in the area before naming the faults. The coseismic fault appears to merge into the Xuankou fault (Figs. 1a, 2a). However, Xuankou fault is drawn as a SE-dipping fault forming a klippen structures (Fig. 1b; see also Chen and Wilson 1996). Thus, the two faults cannot be the same as we drew a geological profile in Fig. 2b (the coseismic fault in blue and Xuankou fault in red at the boundary between the Triassic and Devonian formations). Liu-Zeng et al. (2010, Fig. 11) propose an interesting tectonic evolution of the Hongkou area due to an interplay of NW and SE-dipping faults, but our geological data are not enough to comment on their proposal at this point.

\subsection{High-velocity frictional properties and deformation textures of the Shenxigou fault gouge}

Both GG and BG from the Shenxigou trench site (Figs. 4a and 7a) exhibit marked slip weakening at high slip rates that can be described by an exponential slip weakening law, Eq. (1) (Fig. 9b-d; Table 2 for a summary of slipweakening parameters, peak friction coefficient $\mu_{\mathrm{p}}$, steadystate friction coefficient $\mu_{\mathrm{ss}}$, and slip-weakening distance $D_{\text {c }}$ ). Although GG and BG behave somewhat differently as discussed later, their overall behaviors are similar to reported behaviors of various gouges (e.g., Mizoguchi et al. 2007, 2009; Han et al. 2007b; Brantut et al. 2008; Sone and Shimamoto 2009; De Paola et al. 2011; Di Toro et al. 2011; Togo et al. 2011b; Hou et al. 2012; Yao et al. 2013a). As for the fault gouge from the Longmenshan fault system, the slip-weakening parameters of GG and BG are quite similar to those of six gouges from four fault-zone outcrops (Fig. 12a-c). Thus, the Longmenshan fault zones appear to be quite uniform with respect to the slip-weakening behaviors at high velocities as proposed by $\mathrm{Yao}$ et al. (2013a), even if our data from Shenxigou are added. The marked slip-weakening must have promoted dynamic rupture propagation during the Wenchuan earthquake. Moreover, our data on the rapid recovery of the frictional strength following a seismic fault motion agree well with the results on the Pingxi fault gouge (see comparison of the results from SHS tests in Fig. 12d). Despite those progresses being made, it should be kept in mind that our work as well as most previous work has been conducted under dry conditions with room humidity even though most natural fault zones are likely to be saturated with water. Extending high-velocity friction experiments to controlled pore-pressure conditions is one of the most important tasks remaining in fault mechanics.

Zhang and He (2013) conducted friction experiments on gouge from a few outcrops of the Longmenshan fault system at slip rates of $0.04-5 \mu \mathrm{m} / \mathrm{s}$ and reported that the friction coefficients varied by a factor of three (0.2-0.6) depending on the amount of clay minerals (illite, smectite, and chlorite) contained in the gouge samples. Heterogeneous frictional properties of fault zones at slow slip rates can affect population of earthquakes as demonstrated by earthquake modeling with heterogeneous fault zones (e.g., Ben-Zion 1996, 2008; Hillers et al. 2006). Thus, the heterogeneous frictional properties at slow slip rates may affect earthquake nucleation and microseismicity. Measuring frictional properties of Shenxigou fault gouge at low to intermediate slip rates is left for the future.

The frictional behavior and deformation textures of GG are quite similar to those of gray-blackish gouge from the Pingxi fault zone near the eastern end of the coseismic faults during the Wenchuan earthquakes (Yao et al. 2013a, $2013 b$ ). These gouges have high quartz contents (58\% for GG, $43 \%-66 \%$ for the Pingxi gray-blackish gouge) and high contents of clay minerals $(25 \%$ for GG (illite, illitesmectite mixed layer clay, and chlorite), 26\%-33\% for the gray-blackish gouge (illite and smectite); cf. Table 1 of this paper and Table 1 of Yao et al. (2013a)). Deformed GG and the gray-blackish gouge are characterized by the development of complex and overlapped slip-zone structures (cf. Figs. 13, 12 in Yao et al. (2013a), and Fig. 4 in Yao et al. (2013b)). The overlapped slip-zone structures are very similar to those reported in De Paola et al. (2011), Togo et al. (2011b, 2012), and Sawai et al. (2012). In particular, Togo and Shimamoto (2012) and Sawai et al. (2012) demonstrated that the BET surface area of gouge decreased with increasing displacement, despite extreme grain-size reduction in slip zones, owing to the welding or sintering of gouge particles. Shimamoto and Togo (2012) then proposed that the sintering or welding of gouge, and/ or shear-induced compaction strengthens a slip zone to make the shearing deformation in the narrow slip zone difficult, resulting in a shift of slip zone to less deformed and weaker gouge. The shifting of slip zone forms complex 
deformation of existing slip zones, typically forming overlapped slip zones (Fig. 13b, e and g). In some cases, slip zones were broken into pieces and scattered throughout the gouge, and very erratic frictional behavior was observed in the run (Yao et al. 2013a, Figs. 6d, 11).

The behavior of BG from Shenxigou fault zone is similar to that of black gouge from the Pingxi fault zone described by Yao et al. (2013a). Both gouges contain large amounts of quartz (49\% for BG and $68 \%-83 \%$ for the Pingxi black gouge), fair amounts of clay minerals (32\% for BG (illite, illite-smectite mixed layer clay, and chlorite), and $10 \%-25 \%$ for the black gouge (smectite and illite), and organic carbon (28\% for BG and $3 \%$ for the black gouge); cf. Table 1 and Yao et al. 2013a, Table 1). The carbon content is much greater for BG than for the Pingxi black gouge, but both appear very black in color. The both gouges exhibit abrupt and large drop in friction coefficient just after the peak friction is exceeded, then gradual recovery of friction roughly to the level of peak friction, and finally slip-weakening (cf. Fig. 9d, f of this paper and Figs. 9, 12 of Yao et al. (2013a)). The deformed Pingxi black gouge at a displacement of $0.13 \mathrm{~m}$ (just after the initial drop in friction) was characterized by a very narrow slip zone of about $5 \mu \mathrm{m}$ in width at the gougemoving block boundary and by weakly deformed gouge (Yao et al. 2013a, Fig. 12a). The average shear strain (displacement/slip-zone width) is about $3 \times 10^{4}$. On the other hand, Oohashi et al. (2013, Fig. 7) demonstrated that the friction coefficient of quartz-graphite mixed gouge becomes nearly the same as the steady-state friction coefficient, when the average shear strain of the gouge is $10^{4}$. Thus, Yao et al. (2013a) proposed that the abrupt drop in friction was caused by the formation of a sharp slip zone and that the subsequent strengthening was due to the widening of slip zone associated with the formation of overlapped slip zones. We have not confirmed such an evolution of deformation structures in BG with increasing displacement. However, deformed BG is characterized by narrow slip zones of a few microns in width and by weakly to moderately deformed gouge zones, and overlapped slip zones are quite uncommon (Fig. 14). Narrow slip zones and a wide weakly to moderately deformed gouge of $\mathrm{BG}$ are common features shared with the Pingxi black gouge, although a few overlapped slip zones formed in the latter (cf. Yao et al. 2013a, Fig. 12). Narrow slip zones of BG must have promoted the formation of shiny slickenside surface (Fig. 9b), in marked contrast with less shiny slip surface of GG (Fig. 9a). Graphite might have formed from low-crystalline graphite along the shiny slickenside surface of BG as shown by Oohashi et al. (2011) and Kuo et al. (2014), but we have not confirmed this yet.

Foliated, folded, and disrupted gouge (mixed GG and $\mathrm{BG})$ in the gouge zone next to the coseismic fault during the Wenchuan earthquake (Fig. 7d-f) is closer to deformed GG with overlapped slip zones, rather than to the deformed BG with a few very narrow slip zones. Overlapped slipzone structures are not clear in the Shenxigou gouge probably because of the difference in the scale of observation, but GG and BG are mixed up and sheared in the natural gouge. Folds of slip zones such as those in Fig. 7e did not form in our experiments, but Mizoguchi et al. (2009) experimentally produced folded and disrupted slip zones in Nojima fault gouge. We thus infer that GG dictated the deformation of mixed GG and BG gouge in the Shenxigou fault zone.

Laboratory experiments give insight on the evolution of large-scale natural fault zones. Shimamoto and Togo (2012) suggested that the strengthening of slip zones and subsequent shift of slip zone to less deformed gouge can be an important mechanism for the growth of fault gouge zone (or fault core). Many gouge zones formed in the northwestern side of the Yingxiu-Beichuan fault zone at Bajiao Miao, Hongkou is probably a manifestation of such shifting of slip zones in a natural fault zone. Jumping of a coseismic slip zone to the southeastern margin of the fault zone, where the coseismic fault motion occurred during the Wenchuan earthquake, might have been caused by the strengthening and locking of fault zone at and near the boundary between the Pengguan Massif and Triassic formations. Shenxigou fault zone is similar to the southeastern side of the fault zone at Bajiao Miao because we do not see cataclasites and many gouge zones on the northwest side in Shenxigou. Thus, the jumping of coseismic slip zone might have triggered the formation and activity of fault(s) from Hongkou to Shenxigou. Longmenshan fault system is still evolving, and its evolution history has to be examined based on detailed fault zone studies at different scales.

\section{Conclusions}

We studied internal structures, deformation textures, and constituent minerals of a wide fault zone in Triassic sedimentary rock at Shenxigou in the Longmenshan fault system and conducted high-velocity friction experiments to reproduce the seismic fault motion during the 2008 Wenchuan earthquake. The major outcomes are summarized as follows.

(1) Several outcrops (mostly fault breccia), trench survey of the coseismic slip zone during the Wenchuan earthquake, and a shallow drilling (57 $\mathrm{m}$ deep) reveal that the fault zone is $250-300 \mathrm{~m}$ wide and consists of fault gouge of about $0.5 \mathrm{~m}$ in width next to the coseismic slip zone. The drilling data indicate that the fault dips to $\mathrm{NW}$ by $68^{\circ}$ (its strike is $\mathrm{N} 62^{\circ} \mathrm{E}$ from the 
surface ruptures). Several gouge zones up to about $1 \mathrm{~m}$ in width were recognized on an outcrop and in drill cores, but gouge is not common in wide fault breccia zone. The fault zone is much wider than the fault zone (about $100 \mathrm{~m}$ wide) in Bajiao Miao, Hongkou. The fault zone at Bajiao Miao is a part of the Beichuan fault zone, a major fault zone in the Longmenshan fault system. But the fault zone from Bajiao Miao to Shenxigou is likely to be a branching fault zone from the Beichuan fault zone.

(2) The vertical offset and horizontal displacement during the Wenchuan earthquake at the displaced road were $2.8 \mathrm{~m}$ ( $\mathrm{NW}$ side up) and $4.8 \mathrm{~m}$ (right-lateral), respectively, at the trench site where the wide fault zone is thrust over the Quaternary carbonate conglomerates. Our drilling confirmed the conglomerates down to a depth of $57 \mathrm{~m}$, so that the fault moved vertically at least by $55 \mathrm{~m}$ along the fault and must have experienced earthquakes similar to Wenchuan earthquake about 18 times. An average recurrence interval of earthquakes will be estimated if the age of soil in the conglomerates can be measured.

(3) Fault gouge near the coseismic slip zone was classified into GG and BG, which are deformed in complex manner with overlapping stages of deformation. XRD analyses of six samples revealed that the gouge and fault breccia contain quartz (49-62\%), plagioclase $(9-15 \%)$, calcite $(4-8 \%)$ or dolomite (3-5\%), illite-smectite mixed layer clay (2-14\%), illite (8-15\%), kaolinite (1-3\%), and chlorite (2-6\%) (Table 1). A sample of BG contained $28 \%$ of carbon (TOC analysis), but XRD analysis of a sample with carbonates and silicates dissolved away detected only low-crystalline graphite, but not fully crystallized graphite.

(4) High-velocity friction experiments at normal stresses $\sigma_{\mathrm{n}}$ of $0.6-2.1 \mathrm{MPa}$, slip rates $v$ of $0.1-2.1 \mathrm{~m} / \mathrm{s}$, and under room humidity revealed dramatic weakening of GG and BG at high velocities, characterized by an exponential decay from the peak friction coefficient $\mu_{\mathrm{p}}$ to the steady-state friction coefficient $\mu_{\mathrm{ss}}$ over a slip-weakening distance $D_{\mathrm{c}}$ (see Table 2 for the parameters). Comparison with the results for gouge from other outcrops revealed that the Longmenshan fault zones are quite uniform with respect to the highvelocity weakening properties. High-velocity weakening of gouges must have promoted dynamic rupture propagation during the Wenchuan earthquake. Preliminary results from slide-hold-slide test at $\sigma_{\mathrm{n}}=1.0 \mathrm{MPa}$ and $v=2.1 \mathrm{~m} / \mathrm{s}$ are consistent with previous results on the Pingxi gouge near the eastern end of the Longmenshan fault system and showed very rapid strength recovery following seismic slip (as much as 0.4 in friction coefficient in a hold time of $10 \mathrm{~s})$.

(5) Deformed GG is characterized by overlapped and disrupted slip zones and by multiple slip zones. A slip zone is likely to have strengthened due to shearinduced compaction and/or particle welding to shift the slip zone to weaker gouge. This can be an important mechanism for the shifting of slip zones and broadening of fault zone, and a similar mechanism might have worked on a larger scale to shift the fault slip in Shenxigou away from the Beichuan fault. On the other hand, BG is characterized by a beautiful fault mirror at the gouge-moving block interface and by weakly and almost undeformed gouge zones.

Acknowledgments We thank Kiyokazu Oohashi and Nicolas De Paola for their constructive reviews of our paper which substantially improved this paper. In particular, K. Oohashi pointed out that carbonaceous material in Shenxigou was low-crystalline graphite, rather than amorphous carbon, and provided us with useful references. Y. Wang, S. Ma, T. Shimamoto, and L. Yao conducted field work and friction experiments, and wrote the present paper. H. He and J. Chen did the trench survey, X. Yang, J. Dang, L. Yao, and L. Hou worked on the drilling in the Shenxigou fault zone, and T. Togo contributed to the carbon analysis of the black gouge. We all thank C. He, Y. Zhou, L. Zhang, and other members of Laboratory of Tectonophysics, IGCEA, for their useful discussions and collaboration on the Longmenshan fault project. This work was supported by State Key Laboratory of Earthquake Dynamics (project No. LED2010A03) and Wenchuan Earthquake Fault Scientific Drilling Project (WFSD-09).

\section{References}

Bartlett WL, Friedman M, Logan JM (1981) Experimental folding and faulting of rocks under confining pressure, Part IX. Wrench faults in limestone layers. Tectonophysics 79:255-277

Ben-Zion Y (1996) Stress, slip, and earthquakes in models of complex single-fault systems incorporating brittle and creep deformations. J Geophys Res 101:5677-5706. doi:10.1029/95JB03534

Ben-Zion Y (2008) Collective behavior of earthquakes and faults: continuum-discrete transitions, progressive evolutionary changes, and different dynamic regimes. Rev Geophys 46:1-70. doi:10.1029/2008RG000260

Boutareaud S, Boullier A-M, Andréani M, Calugaru D-G, Beck P, Song SR, Shimamoto T (2010) Clay clast aggregates in gouges: new textural evidence for seismic faulting. J Geophys Res 115(B2):B02408. doi:10.1029/2008JB006254

Brantut N, Schubnel A, Rouzaud JN, Brunet F, Shimamoto T (2008) High-velocity frictional properties of a clay-bearing fault gouge and implications for earthquake mechanics. J Geophys Res 113:B10401. doi:10.1029/2007JB005551

Burchfiel B, Royden L, van Der Hilst R, Hager B, Chen Z, King R, Li C, Lu J, Yao H, Kirby E (2008) A geological and geophysical context for the Wenchuan earthquake of 12 May 2008, Sichuan, People's Republic of China. GSA Today 18(7):4-11

Chen SF, Wilson CJL (1996) Emplacement of the Longmen Shan Thrust-Nappe Belt along the eastern margin of the Tibetan Plateau. J Struct Geol 18:413-430

Chen J, Yang X, Ma S, Spiers CJ (2013a) Mass removal and clay mineral dehydration/rehydration in carbonate-rich surface 
exposures of the 2008 Wenchuan Earthquake fault: geochemical evidence and implications for fault zone evolution and coseismic slip. J Geophys Res 118:1-23. doi:10.1002/jgrb.50089

Chen J, Yang X, Duan Q, Shimamoto T, Spiers CJ (2013b) Importance of thermochemical pressurization in the dynamic weakening of the Longmenshan fault during the 2008 Wenchuan earthquake: inferences from experiments and modeling. J Geophys Res 118:4145-4169. doi:10.1002/jgrb.50260

Chen J, Yang X, Yao L, Ma S, Shimamoto T (2013c) Frictional and transport properties of the 2008 Wenchuan earthquake fault zone: implications for coseismic slip-weakening mechanisms. Tectonophysics 603:237-256

De Paola N, Hirose T, Mitchell T, Di Toro G, Viti C, Shimamoto T (2011) Fault lubrication and earthquake propagation in thermally unstable rocks. Geology 39:35-38

Densmore AL, Ellis M A, Li Y, Zhou R, Hancock G S and Richardson N (2007) Active tectonics of the Beichuan and Pengguan faults at the eastern margin of the Tibetan Plateau. Tectonics 26:TC4005. doi:10.1029/2006TC001987

Di Toro G, Han R, Hirose T, De Paola N, Nielsen S, Mizoguchi K, Ferri F, Cocco M, Shimamoto T (2011) Fault lubrication during earthquakes. Nature 471:494-498

Godard V, Pik R, Lavé J, Cattin R, Tibari B, de Sigoyer J, Pubellier M and Zhu J (2009) Late Cenozoic evolution of the central Longmen Shan, eastern Tibet: insight from (U-Th)/He thermochronometry. Tectonics 28:TC5009. doi:10.1029/2008TC002 407

Han R, Shimamoto T, Hirose T, Ree J-H, Ando J (2007a) Ultralow friction of carbonate faults caused by thermal decomposition. Science 316:878-881

Han R, Shimamoto T, Ando J, Ree J-H (2007b) Seismic slip record in carbonate-bearing fault zones: an insight from high-velocity friction experiments on siderite gouge. Geology 35:1131-1134

He H, Sun Z, Wang S, Wang J, Dong S (2008) Rupture of the Ms 8.0 Wenchuan Earthquake. Seismol Geol 30(2):359-362 (in Chinese with English abstract)

Hillers G, Ben-Zion Y, Mai PM (2006) Seismicity on a fault controlled by rate- and state-dependent friction with spatial variations of the critical slip distance. J Geophys Res 111:B01403. doi:10.1029/2005JB003859

Hirose T, Bystricky M (2007) Extreme dynamic weakening of faults during dehydration by coseismic shear heating. Geophys Res Lett 34:L14311

Hirose T, Shimamoto T (2005) Growth of molten zone as a mechanism of slip weakening of simulated faults in gabbro during frictional melting. J Geophys Res 110:B05202. doi:10. 1029/2004JB003207

Hoefs J (2004) Stable isotope geochemistry, 5th edn. Springer, New York

Hou L, Ma S, Shimamoto T, Chen J, Yao L, Yang X, Okimura Y (2012) Internal structures and high-velocity frictional properties of a bedding-parallel carbonate fault at Xiaojiaqiao outcrop activated by the 2008 Wenchuan earthquake. Earthq Sci 25:197-217

Itaya $T$ (1981) Carbonaceous material in pelitic schists of the Sanbagawa metamorphic belt in central Shikoku, Japan. Lithos $14: 215-224$

Jin W, Tang L, Yang K, Wan G, Lu Z (2010) Segmentation of the Longmen Mountains thrust belt, western Sichuan foreland basin, SW China. Tectonophysics 485:107-121

Kirby E, Reiners P W, Krol M A, Whipple K X, Hodges K V, Farley K A, Tang W and Chen Z (2002) Late Cenozoic evolution of the eastern margin of the Tibetan Plateau: Inferences from ${ }^{40} \mathrm{Ar} /{ }^{39} \mathrm{Ar}$ and (U-TH)/He thermochronology. Tectonics 21:1001. doi:10. 1029/2000TC001246
Kuo L, Li H, Smith SAF, Di Toro G, Suppe J, Song S, Nielsen S, Sheu H, Si J (2014) Gouge graphitization and dynamic fault weakening during the $2008 M_{\mathrm{W}} 7.9$ Wenchuan earthquake. Geology 42:47-50. doi:10.1130/G34862.1

Li H, Wang H, Xu Z, Si J, Pei J, Li T, Huang Y, Song S, Kuo L, Sun Z, Chevalier ML, Liu D (2013) Characteristics of the fault-related rocks, fault zones and the principal slip zone in the Wenchuan Earthquake Fault Scientific Drilling Project Hole-1 (WFSD-1). Tectonophysics 584:23-42. doi:10.1016/j.tecto.2012.08.021

Li H, Xu Z, Niu Y, Kong G, Huang Y, Wang H, Si J, Sun Z, Pei J, Gong Z, Chevalier ML, Liu D (2014) Structural and physical property characterization in the Wenchuan earthquake fault scientific drilling project-hole 1 (WFSD-1). Tectonophysics 619(620):86-100

Lin A, Ren Z, Jia D, Wu X (2009) Co-seismic thrusting rupture and slip distribution produced by the $2008 M_{\mathrm{W}} 7.9$ Wenchuan earthquake, China. Tectonophysics 471:203-215

Lin A, Ren Z, Kumahara Y (2010) Structural analysis of the coseismic shear zone of the $2008 M_{\mathrm{W}} 7.9$ Wenchuan earthquake, China. J Struct Geol 32:781-791

Liu-Zeng J, Zhang Z, Wen L, Tapponnier P, Sun J, Xing X, Hu G, Xu Q, Zeng L, Ding L, Ji C, Hudnut KW, van der Woerd J (2009) Co-seismic ruptures of the 12 May 2008, $M_{\mathrm{S}}$ 8.0 Wenchuan earthquake, Sichuan: East-west crustal shortening on oblique, parallel thrusts along the eastern edge of Tibet. Earth Planet Sci Lett 286:355-370

Liu-Zeng J, Wen L, Sun J, Zhang Z, Hu G, Xing X, Zeng L, Xu Q (2010) Surficial slip and rupture geometry on the Beichuan fault near Hongkou during the $M_{\mathrm{W}} 7.9$ Wenchuan earthquake, China. Bull Seismol Soc Am 100:2615-2650. doi:10.1785/0120090316

Logan JM, Dengo CA, Higgs NG, Wang ZZ (1992) Fabrics of experimental fault zones: their development and relationship to mechanical behavior. In: Evans B, Wong TF, Brace WF (eds) Fault mechanics and transport properties of rocks. Academic Press, London, pp 33-67

Mizoguchi K, Hirose T, Shimamoto T, Fukuyama E (2007) Reconstruction of seismic faulting by high-velocity friction experiments: an example of the 1995 Kobe earthquake. Geophys Res Lett 34:L01308

Mizoguchi K, Hirose T, Shimamoto T, Fukuyama E (2009) Highvelocity frictional behavior and microstructure evolution of fault gouge obtained from Nojima fault, southwest Japan. Tectonophysics 471:285-296

Moore DM, Reynolds RC Jr (1997) X-ray diffraction and the identification and analysis of clay minerals. Oxford University Press, Oxford

Nakamura Y, Akai J (2013) Microstructural evolution of carbonaceous material during graphitization in the Gyoja-yama contact aureole: HRTEM, XRD and Raman spectroscopic study. J Mineral Petrol Sci 108:131-143

Oohashi K, Hirose T, Shimamoto T (2011) Shear-induced graphitization of materials during seismic fault motion: experiments and possible implications for fault mechanics. J Struct Geol 33:1122-1134

Oohashi K, Hirose T, Kobayashi K, Shimamoto T (2012) The occurrence of graphite-bearing fault rocks in the Atotsugawa fault system, Japan: origins and implications for fault creep. J Struct Geol 38:39-50

Oohashi K, Hirose T, Shimamoto T (2013) Graphite as a lubricating agent in fault zones: an insight from low- to high-velocity friction experiments on a mixed graphite-quartz gouge. J Geophys Res Solid Earth 118. doi:10.1002/jgrb.50175

Ran Y, Chen L, Chen J, Wang H, Chen G, Yin J, Shi X, Li C, Xu X (2010) Paleoseismic evidence and repeat time of large earthquakes at three sites along the Longmenshan fault zone. Tectonophysics 491:141-153 
Sawai M, Shimamoto T, Togo T (2012) Reduction in BET surface area of Nojima fault gouge with seismic slip and its implication for the fracture energy of earthquakes. J Struct Geol 38:117-138

Shimamoto T, Togo T (2012) Earthquakes in the lab. Science 338:54-55

Shimamoto T, Tsutsumi A (1994) A new rotary-shear high-speed frictional testing machine: its basic design and scope of research. J Tectonic Res Group Jpn 39:65-78 (in Japanese with English abstract)

Si J, Li H, Kuo L, Pei J, Song S, Wang H (2014) Clay mineral anomalies in the Yingxiu-Beichuan fault zone from the WFSD-1 drilling core and its implication for the faulting mechanisms during the 2008 Wenchuan earthquake $\left(M_{\mathrm{W}} 7.9\right)$. Tectonophysics 619(620):171-178

Sibson RH (1977) Fault rocks and fault mechanisms. J Geol Soc 133:191-213

Sichuan Bureau of Chinese Geological Survey (1976) Regional Geologic Map (1:200000 scale) of the Guanxian area

Sone H, Shimamoto T (2009) Frictional resistance of faults during accelerating and decelerating earthquake slip. Nat Geosci 2:705-708

Togo T, Shimamoto T (2012) Energy partition for grain crushing in quartz gouge during subseismic to seismic fault motion: an experimental study. J Struct Geol 38:139-155

Togo T, Shimamoto T, Ma S, Wen X, He H (2011a) Internal structure of Longmenshan fault zone at Hongkou outcrop, Sichuan, China, that caused the 2008 Wenchuan earthquake. Earthq Sci 24:249-265

Togo T, Shimamoto T, Ma S, Hirose T (2011b) High-velocity frictional behavior of Longmenshan fault gouge from Hongkou outcrop and its implications for dynamic weakening of fault during the 2008 Wenchuan earthquake. Earthq Sci 24:267-281

Wang H, Li H, Si J, Sun Z, Huang Y (2014) Internal structures of the Wenchuan earthquake fault zone, revealed by surface outcrop and WFSD-1 drilling core investigation. Tectonophysics 619(620):101-114

Xu X, Wen X, Yu G, Chen G, Klinger Y, Hubbard J, Shaw J (2009a) Coseismic reverse- and oblique-slip surface faulting generated by the $2008 M_{\mathrm{W}} 7.9$ Wenchuan earthquake, China. Geology 37:515-518. doi:10.1130/G25462A.1

Xu Z, Ji S, Li H, Hou L, Fu X, Cai Z (2009b) Uplift of the Longmen Shan range and the Wenchuan earthquake. Episodes 31:291-301

Yao L, Ma S, Shimamoto T, Li H (2012) Intermediate to highvelocity frictional properties of Longmenshan fault gouge from WFSD- 1 cores and outcrops. American Geophysical Union, Fall Annual Meeting, San Francisco, T44B-08

Yao L, Ma S, Shimamoto T, Togo T (2013a) Structures and highvelocity frictional properties of the Pingxi fault zone in the Longmenshan fault system, Sichuan, China, activated during the 2008 Wenchuan earthquake. Tectonophysics 599:135-156

Yao L, Shimamoto T, Ma S, Han R and Mizoguchi K (2013b) Rapid postseismic strength recovery of Pingxi fault gouge from the Longmenshan fault system: experiments and implications for the mechanisms of high-velocity weakening of faults. J Geophys Res 118. doi:10.1002/jgrb.50308

Zhang P (2013a) A review on active tectonics and deep crustal processes of the Western Sichuan region, eastern margin of the Tibetan Plateau. Tectonophysics 584:7-22

Zhang P (2013b) Beware of slowly slipping faults. Nat Geosci 6:323-324

Zhang L, He C (2013) Frictional properties of natural gouges from Longmenshan fault zone ruptured during the Wenchuan $M_{\mathrm{W}} 7.9$ earthquake. Tectonophysics 594:149-164

Zhang P, Wen X, Shen Z, Chen J (2010) Oblique, high-angle, listricreverse faulting and associated development of strain: The Wenchuan earthquake of May 12, 2008, Sichuan, China. Annu Rev Earth Planet Sci 38:353-382 